\title{
Article \\ Influence of Small Vehicle on Transiting Test Method for Measuring Building Wind Pressure Coefficients
}

\author{
Shengli $\mathrm{Li}^{1,2}{ }^{\mathbb{C}}$, Xin Liu ${ }^{2,3, *}$,, Qing $\mathrm{Li}^{2}$, Wudi Gao ${ }^{2}$ and Pan Guo ${ }^{2}$ \\ 1 School of Civil Engineering, Zhengzhou University of Industry Technology, Zhengzhou 450001, China; \\ 1s1@zzu.edu.cn \\ 2 School of Civil Engineering, Zhengzhou University, Zhengzhou 450001, China; lq209@gs.zzu.edu.cn (Q.L.); \\ gaowudi@gs.zzu.edu.cn (W.G.); guopan@zzu.edu.cn (P.G.) \\ 3 School of Civil and Environmental Engineering, Harbin Institute of Technology (Shenzhen), \\ Shenzhen 518000, China \\ * Correspondence: 21b954008@stu.hit.edu.cn; Tel.: +86-152-1705-9505
}

Citation: Li, S.; Liu, X.; Li, Q.;

Gao, W.; Guo, P. Influence of Small Vehicle on Transiting Test Method for Measuring Building Wind Pressure Coefficients. Symmetry 2021, 13, 1726. https://doi.org/10.3390/

sym13091726

Academic Editor: Jan Awrejcewicz

Received: 31 August 2021

Accepted: 10 September 2021

Published: 17 September 2021

Publisher's Note: MDPI stays neutral with regard to jurisdictional claims in published maps and institutional affiliations.

Copyright: () 2021 by the authors. Licensee MDPI, Basel, Switzerland. This article is an open access article distributed under the terms and conditions of the Creative Commons Attribution (CC BY) license (https:// creativecommons.org/licenses/by/ $4.0 /)$.

\begin{abstract}
The transiting test method is a new approach for structural wind resistance research. However, traffic on the test road inevitably influences test results. In this study, the symmetrical CAARC standard tall building model was used to investigate the influence of a small vehicle near the test vehicle. A small vehicle was set up as an interference vehicle to drive around the test vehicle under different cases during the test. Results indicate that the mean wind pressure coefficient during the overtaking period is higher than that during the no overtaking period. The enlarged relative velocity and the small test vehicle velocity increase the overtaking interference and the data calculation time required to eliminate the overtaking influence. The overtaking influence only occurs if the test vehicle is overtaken by the small vehicle in the adjacent lane. The influence of the overtaking behavior of a small vehicle can be eliminated after the data calculation time exceeds $26 \mathrm{~s}$. Moreover, the wake of small interference vehicle no longer influences the transiting test results after the spacing reaches $24 \mathrm{~m}$.
\end{abstract}

Keywords: transiting test; CAARC standard model; wind pressure coefficient; overtaking; vehicle spacing

\section{Introduction}

There have been many cases of strong winds destroying buildings and structures [1]. Wind loads threaten not only the safety of high-rise structures but also the building's suitability and durability [2,3]. Wind resistance research has become crucial with the increasing number and height of high-rise buildings. Wind resistance is also a key control factor in the design and construction of high-rise buildings [3]. In recent years, many researchers have successfully conducted in-depth studies on the wind resistance of highrise buildings [4-6]. Research methods in the field of wind engineering include the wind tunnel test [7-10], numerical simulations [11-13], and field measurements [14,15]. The transiting test is a new method for investigating structural wind resistance using the stable relative wind field formed on the roof of a traveling vehicle [16,17]. The model is placed on the roof of the test vehicle during the test, and the relative wind velocity is changed through the test vehicle velocity. Compared with the wind tunnel test, the transiting test has the advantages of simplicity, low test cost, and no blocking effect. However, the disadvantage is that some factors under a normal road environment can influence the test results. Investigating and eliminating the influence of interference factors can improve the applicability, accuracy, and reliability of the transiting test.

Research on the transiting test method has progressed considerably. The feasibility of this method has been verified with the CAARC standard model [16] and the triangular prism model [17]. The effect of end plates on the aerodynamic coefficient of the triangular 
prism model has also been explored [18]. In addition, Guo et al. examined the galloping of iced conductors via the transiting test method [19].

The flow field on the road is unstable due to the presence of vehicles and natural wind [20], and the overtaking process has a considerable influence on the aerodynamic characteristics of a vehicle [21-24]. The numerical simulation results in Sun et al. [25] showed that varying lateral distances affect the flow field around the vehicle differently when overtaking. Howell et al. [26] found that a small lateral distance increases the peak value of each aerodynamic parameter. In addition, different relative velocities also have varying effects on the flow field around two vehicles [27]. Furthermore, the relative velocity does not affect the trends of the aerodynamic coefficient curves of two vehicles, but it can affect their peak value [28]. Uystepruyst and Krajnović [29] numerically simulated the overtaking process using the Ahmed model with different relative velocities during overtaking; they obtained various influences on the aerodynamics of the overtaken vehicle. In addition to the overtaking behavior, the wake formed by the traveling vehicle could affect the flow field over a long distance behind and affect the vehicle behind $[27,30]$. The change curve of the aerodynamic coefficient with longitudinal distance during the overtaking process in Noger et al. [31] demonstrated that the vehicle in front could also affect the aerodynamic coefficient of the vehicle in the rear within a certain distance after overtaking. Liu et al. [21] also presented that the flow field around the rear vehicle is affected by the front vehicle even after overtaking within a certain distance. The simulation results in Kui et al. [32] showed that the front truck affects the rear truck over a long distance. The influence of the rear vehicle varies with the vertical spacing [33]. The frequency of small vehicles on the test road is high. Small vehicles are often situated near the test vehicle, and the test vehicle is often overtaken by other vehicles due to its low velocity. The accuracy of transiting test results is influenced by these conditions. To explore the influence of small vehicles on the test results, research is conducted from the perspective of overtaking and no overtaking. The research content is specifically divided into the investigations of relative velocity during overtaking, test vehicle velocity during overtaking, overtaking lane, and wake interference with no overtaking. The influence of the small vehicle in transiting test is summarized by comparing the test results of the wind pressure coefficient of the CAARC standard model. This study aims to provide a reference for subsequent transiting tests, and improve the accuracy and reliability of the transiting test.

\section{Experimental Methods}

\subsection{Model and Transiting Test Facility}

The CAARC (Commonwealth Advisory Aeronautical Research Council) standard tall building model [34] has been widely used in wind engineering research [35-40]. This model with a scale ratio of 1:300 was used in this experiment. The model dimensions are $101.6 \mathrm{~mm}(\mathrm{~L}) \times 152.4 \mathrm{~mm}(\mathrm{~B}) \times 609.6 \mathrm{~mm}(\mathrm{H})$. Twenty measuring points (five measuring points on each surface) are symmetrically arranged at $2 / 3$ of the height of the model, as shown in Figure 1. According to the direction of travel and incoming flow, surfaces I, II, III, and IV are the windward, inner crosswind, leeward, and outer crosswind surfaces, respectively.

Figure 2 shows a physical diagram of the transiting test facility. The test vehicle is a car, and a test platform with a size of $900 \mathrm{~mm} \times 600 \mathrm{~mm}$ is placed on the sunroof. The test model is fixed at the center of the test platform, and a pitot tube is fixed on one side to measure the total and static pressure of the incoming flow. 


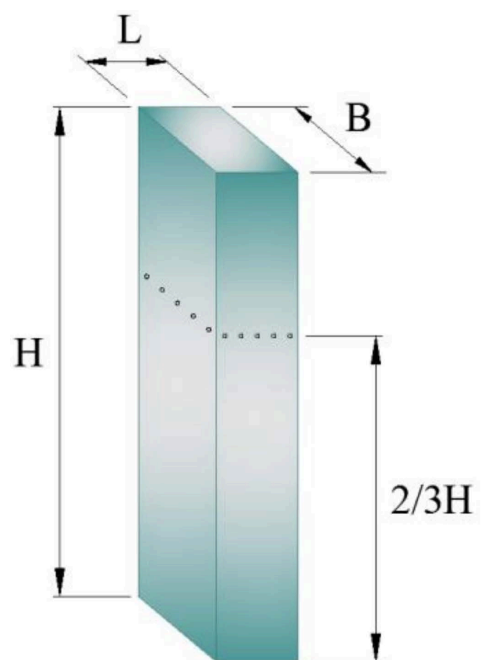

(a)

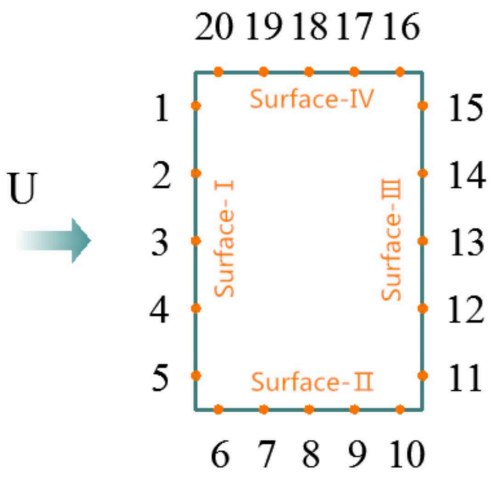

(b)

Figure 1. CAARC model and measurement point distribution. (a) Model size and position of measurement points; (b) distribution of measurement points and number of each surface.

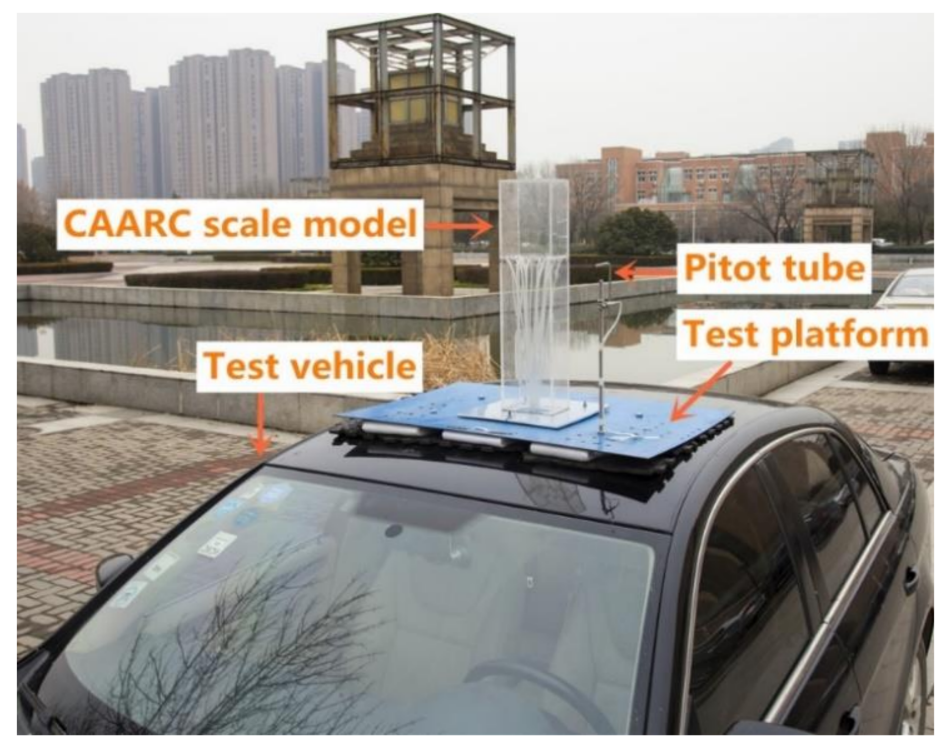

Figure 2. Transiting test facility.

\subsection{Wind Pressure Measuring Equipment}

The wind pressure measurement system is composed of 22 high-frequency pressure sensors (Figure 3) and a multichannel USB data acquisition card. The range of the pressure sensors is $\pm 2 \mathrm{kPa}$, the accuracy grade is $0.25 \%$, the frequency can reach $4 \mathrm{kHz}$, and the output voltage value is $0-5 \mathrm{~V}$. The acquisition card whose maximum sampling frequency can reach $250 \mathrm{kHz}$ and system accuracy is $0.01 \%$ is used for the storage and management of wind pressure data. The pressure sensors are placed in the test vehicle and connected to the roof model through flexible pipes. The wind pressure coefficient of each measurement point can be expressed as follows [16,41]:

$$
C_{p}=\frac{P_{i}-P_{\infty}}{0.5 \rho U^{2}}
$$




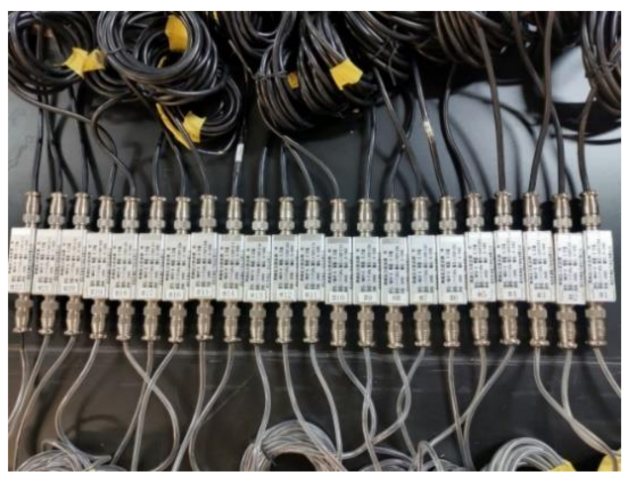

Figure 3. High-frequency pressure sensor.

The pitot tube (as shown in Figure 2) and high-frequency pressure sensors are used to measure the total pressure and static pressure of the roof flow field. Wind velocity can be calculated according to the Bernoulli equation as follows [42]:

$$
U=\sqrt{\frac{2\left(P_{0}-P_{\infty}\right)}{\rho}}
$$

When Formula (2) is substituted into (1), the wind pressure coefficient can be expressed as

$$
C_{p}=\frac{P_{i}-P_{\infty}}{P_{0}-P_{\infty}}
$$

The mean and fluctuating wind pressure coefficient is expressed as follows:

$$
\begin{gathered}
\overline{C_{p}}=\frac{1}{n} \int_{t_{1}}^{t_{2}} C_{p} d t \\
C_{p}^{\prime}=\sqrt{\frac{1}{n} \sum_{k=1}^{n}\left(C_{p, k}-\overline{C_{p}}\right)^{2}}
\end{gathered}
$$

where $P_{i}$ is the pressure value of measuring point $i, P_{0}$ and $P_{\infty}$ are, respectively, the total pressure and static pressure of incoming flow, $U$ is the mean wind velocity of incoming flow, $\rho\left(1.225 \mathrm{~kg} / \mathrm{m}^{3}\right)$ is the air density, $C_{p}$ is the wind pressure coefficient, $t_{1}$ and $t_{2}$ are, respectively, the initial and end times of the sampling duration for calculating mean wind pressure coefficients, $n$ is the number of wind pressure data within the sampling duration, $C_{p, k}$ is the $k$-th wind pressure data value, and $\overline{C_{p}}$ and $C_{p i}^{\prime}$ are the mean wind pressure coefficient and fluctuating wind pressure coefficient.

\subsection{Test Road Introduction}

The test road section should meet the conditions of flatness, straightness, and low traffic to reduce the influence of the road environment on the transiting test results. The road section from the Yulong Station to the Zhongyuan West Road Station of the Zhengzhou Bypass Expressway in China was selected as the research area for this experiment. This area is a two-way, six-lane road with a median strip, as shown in Figure 4. This road section meets the conditions required in the experiment. In addition, the experiment was performed under a little to no natural wind condition to eliminate natural wind interference. Considering the barrier effect of the median strip on the air flow, the experiment ignored the influence of reverse traffic on the flow field around the test vehicle. 


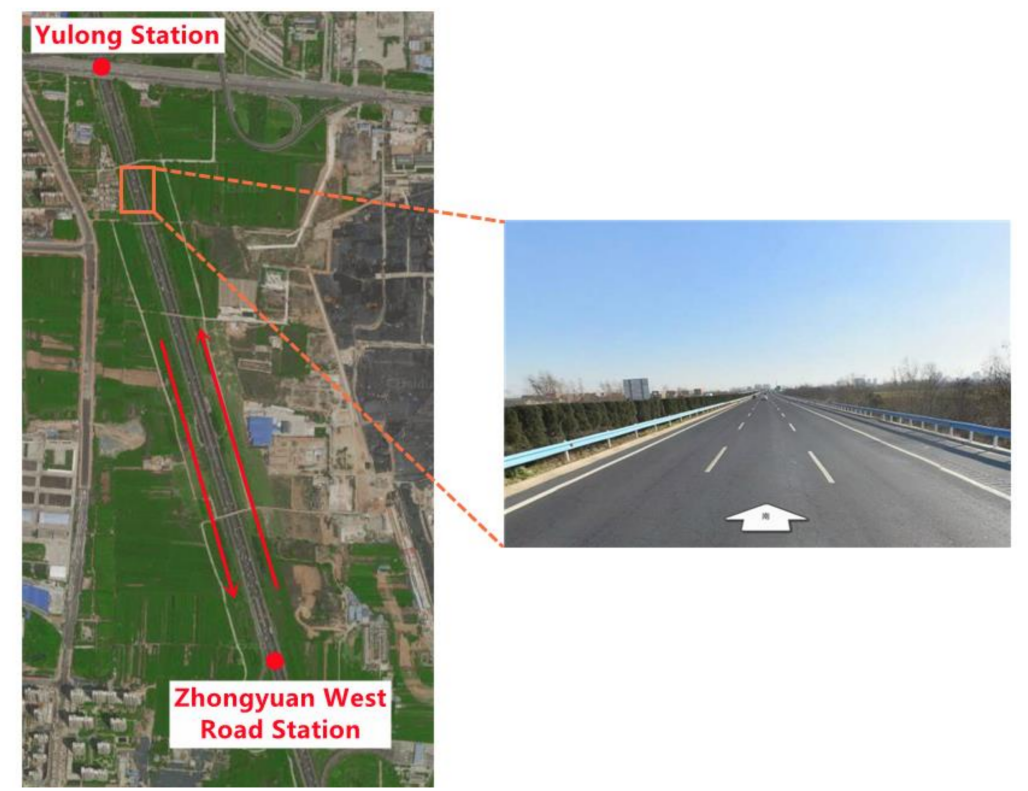

Figure 4. Test road section.

The wind field of the vehicle roof can also be slightly influenced by the velocity of the vehicle when the road conditions are good and the surrounding wind is minimal. Li et al. [16] demonstrated that the wind field on the roof of the test vehicle increased in uniformity as the vehicle velocity increased. However, considering safety, the velocity of the test vehicle should not be too high. The velocity of the test vehicle in this experiment is 60,72 , and $90 \mathrm{~km} / \mathrm{h}$. Traveling on the same three-lane section, the interference and test vehicles undergo two overtaking behavior cases, i.e., overtaking in the adjacent lanes and overtaking separated by one lane, as shown in Figure 5.

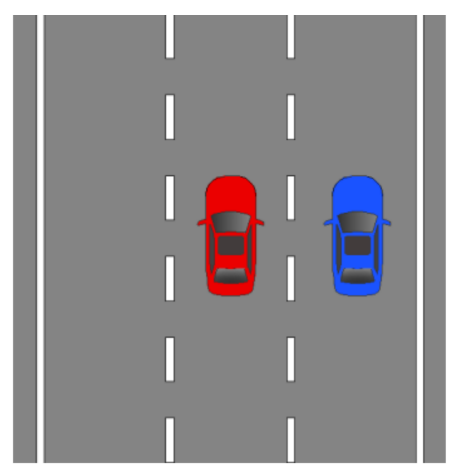

(a)

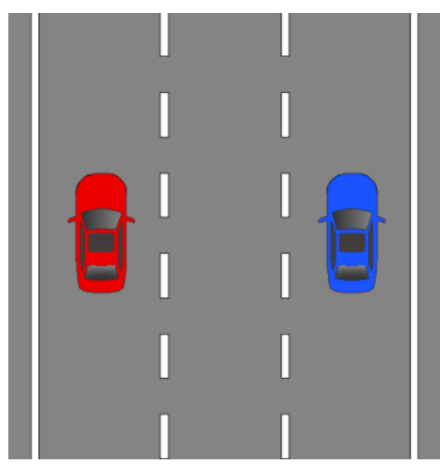

(b)

Figure 5. Positional relationship between the test and interference vehicles during overtaking. (a) Overtaking in the adjacent lane; (b) overtaking separated by one lane; note: $\square$ test vehicle,

a interference vehicle.

\subsection{Classification of Vehicle Size}

Bhautmage et al. [43] showed that the wakes formed by vehicles of different sizes are significantly different and have different degrees of influence on the flow field. In accordance with the vehicle types on the test road observed in the previous period and in reference to the classification of different vehicle sizes [44-46], the size classification of small and non-small vehicles on the test road section is shown in Table 1 . The test vehicle is a small car, which belongs to the small vehicle classification, and an SUV is chosen as the small interference vehicle. 
Table 1. Classification criteria for different types of vehicles (unit: m).

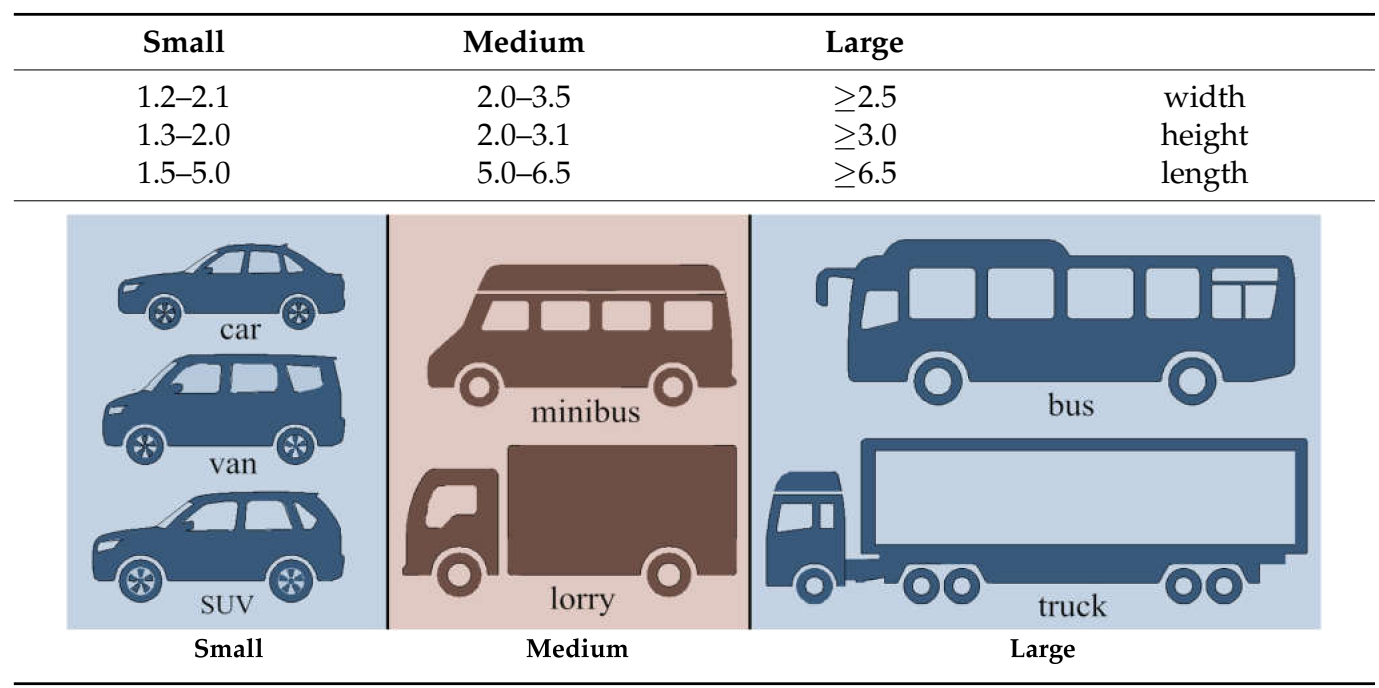

\section{Results and Discussion}

\subsection{Influence of Relative Velocity during Overtaking}

To discuss the influence of the different relative velocities of interference and test vehicles on the model test results during overtaking, the test vehicle maintained a constant velocity of $72 \mathrm{~km} / \mathrm{h}$. Moreover, the interference vehicle overtook the test vehicle in the adjacent lane at velocities of 80,85 , and $90 \mathrm{~km} / \mathrm{h}$, resulting in relative velocities of 8,13 , and $18 \mathrm{~km} / \mathrm{h}$, respectively. Figures $6-8$ present the time history of wind pressure coefficients at the representative measurement points on each surface (intermediate measuring point on each surface) for the three relative velocities. The overtaking period in the figure is the period during which the wind pressure coefficient is influenced by the overtaking behavior, and the solid yellow lines represent the mean wind pressure coefficients for the three periods before, during, and after overtaking. The figure shows that the fluctuations in the wind pressure coefficient of the windward surface at the three relative vehicle velocities during overtaking are small, and their average values are only slightly higher than those before and after overtaking. This finding shows that the influence on the windward surface is minimal. Compared with the wind pressure coefficient of the windward surface, those of the leeward surface and the two crosswind surfaces are more considerably influenced. The wind pressure coefficient remarkably fluctuates during overtaking, and its average value is higher than those before and after overtaking. The main performance of the wind pressure coefficient during the entire overtaking process is characterized by the similar mean wind pressure coefficients before and after the overtaking, which are lower than in the overtaking period, and the time history of the wind pressure coefficient is raised during overtaking. This feature is particularly clear on surfaces II, III, and IV, and the three sets of pictures show that the large relative velocity enhances the bulge of the wind pressure coefficient during overtaking. This finding indicates that the large relative velocity increases the influence of overtaking behavior. 

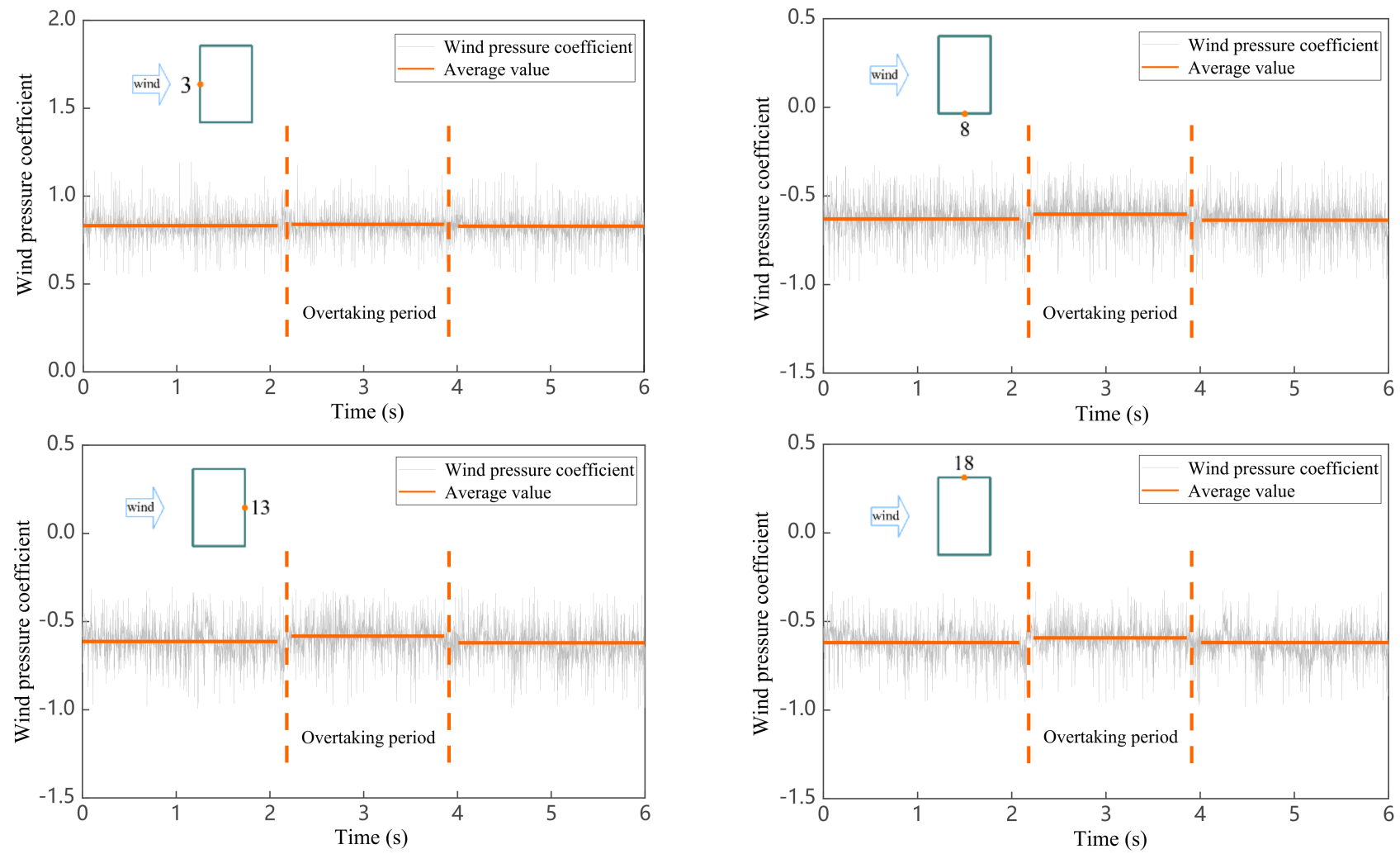

Figure 6. Time history of the wind pressure coefficient of measurement points 3, 8, 13, and 18 when overtaking in the adjacent lane (test vehicle: $72 \mathrm{~km} / \mathrm{h}$, interference vehicle: $80 \mathrm{~km} / \mathrm{h}$ ).
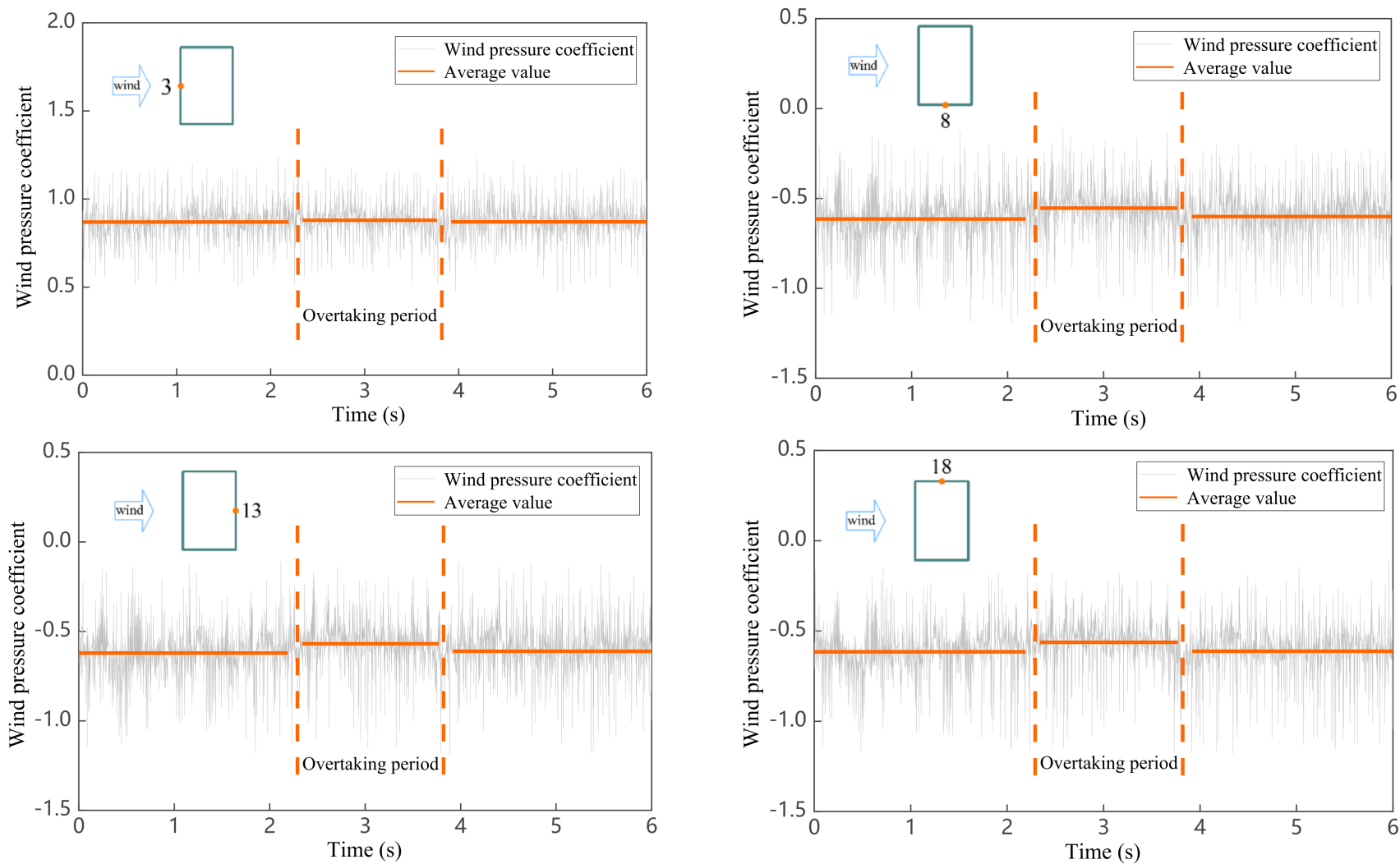

Figure 7. Time history of the wind pressure coefficient of measurement points $3,8,13$, and 18 when overtaking in the adjacent lane (test vehicle: $72 \mathrm{~km} / \mathrm{h}$, interference vehicle: $85 \mathrm{~km} / \mathrm{h}$ ). 

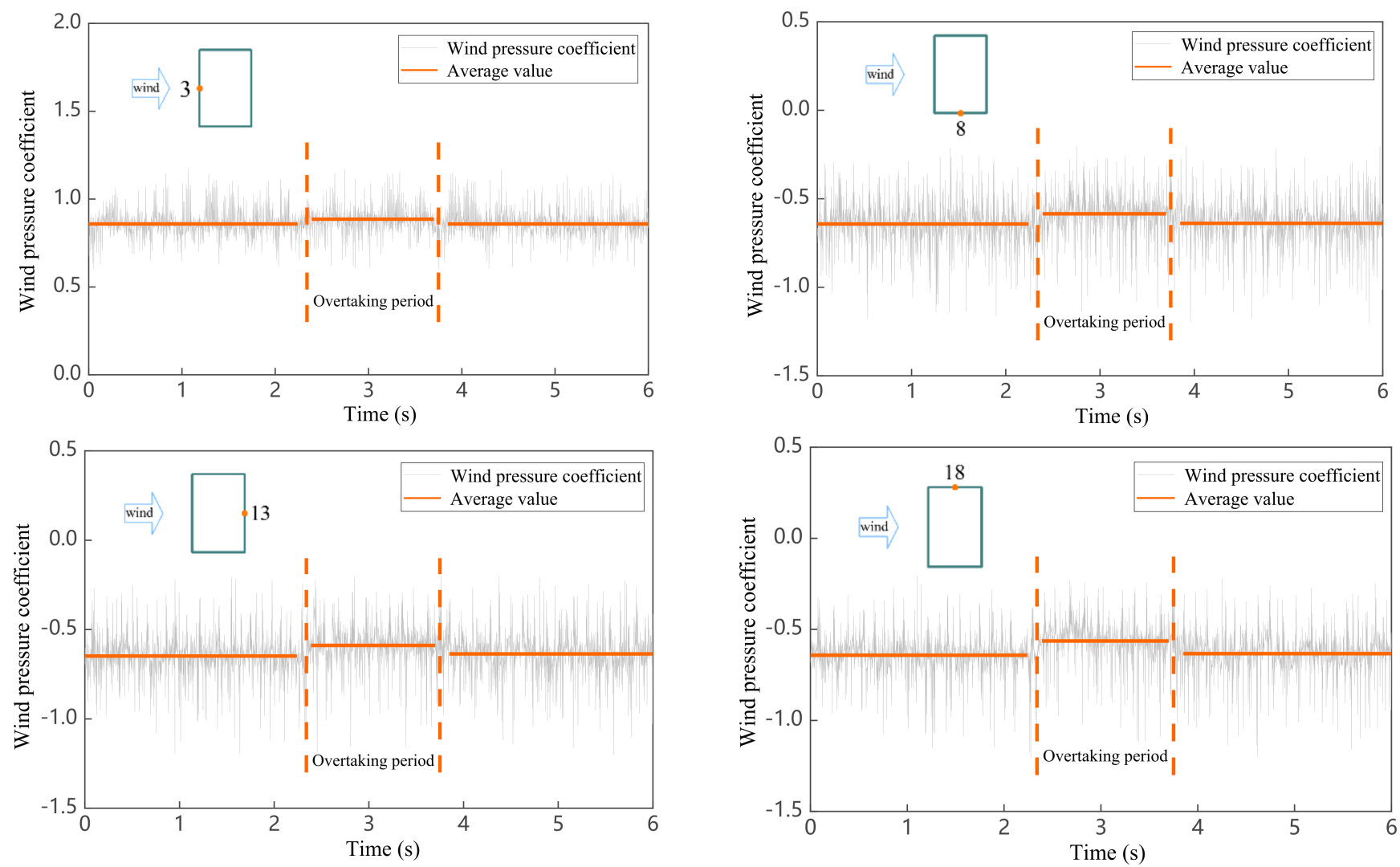

Figure 8. Time history of the wind pressure coefficient of measurement points $3,8,13$, and 18 when overtaking in the adjacent lane (test vehicle: $72 \mathrm{~km} / \mathrm{h}$, interference vehicle: $90 \mathrm{~km} / \mathrm{h}$ ).

The mean wind pressure coefficients at each measurement point of the CAARC model at each relative velocity for the overtaking period and excluding the overtaking period are shown in Figure 9. The test results are compared with those of the wind tunnel test $[34,35,47]$ and the numerical simulation of smooth inflow [48]. The curves of the mean wind pressure coefficient in the overtaking period and excluding the overtaking period are consistent with the results of the wind tunnel test. Combined with the research results in Lee [49], the bulges of the mean wind pressure coefficient curves on the leeward surface in this experiment are unclear (surface III) because the flow field on the roof of the test vehicle is relatively smooth. Hence, the overall trends of the curves are more consistent with the numerical simulation result of smooth inflow. The overtaking behavior only increases the value of the mean wind pressure coefficient at each measurement point and makes the curve deviate (especially reflected in the negative pressure area) but does not influence its overall trend.

To quantify the deviation in the mean wind pressure coefficient of each surface due to the overtaking behavior and the overall influence of the overtaking behavior on all measurement points, the deviation calculation formulas are introduced as follows [47]:

$$
\begin{gathered}
\text { Deviation (\%) }=\frac{1}{n} \sum_{i}^{n} \frac{\overline{C_{p i 1}}-\overline{C_{p i 2}}}{\overline{C_{p i 2}}} \times 100 \% \\
\text { Absolute deviation (\%) }=\frac{1}{20} \sum_{1}^{20}\left|\frac{\overline{C_{p i 1}}-\overline{C_{p i 2}}}{\overline{C_{p i 2}}}\right| \times 100 \%
\end{gathered}
$$

where $n$ is the number of measurement points participating in the current deviation calculation (set to 5 on each surface), $\overline{C_{p i 1}}$ is the mean wind pressure coefficient at measurement point $i$ during overtaking interference period, and $\overline{C_{p i 2}}$ is the mean wind pressure coefficient at measurement point $i$ without overtaking interference. 


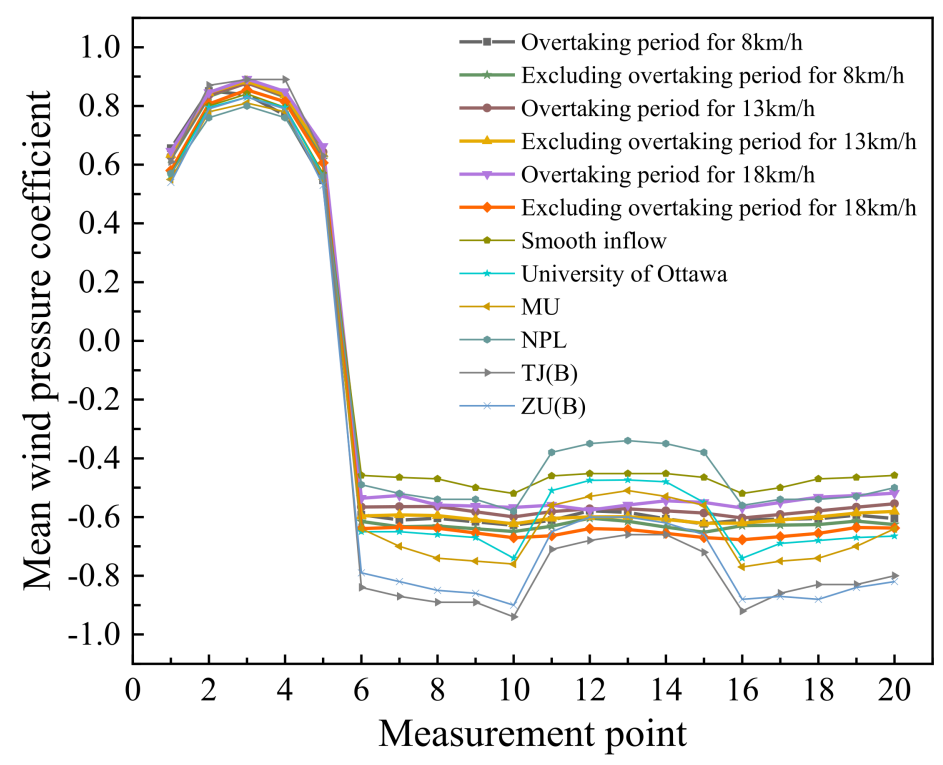

Figure 9. Mean wind pressure coefficients of each measurement point at different relative velocities during the overtaking period and excluding the overtaking period.

Figure 10 shows the deviation in the mean wind pressure coefficients between the overtaking period and excluding the overtaking period at the three relative velocities. The absolute value reflects the magnitude of the deviation. The four surfaces of the model show the same law, that is, the large relative velocity increases the deviation on each surface. By contrast, the deviation in the windward surface among the four surfaces in the same group is the smallest and significantly smaller than the three other surfaces. The deviations in the windward surfaces of the first two groups are less than $2 \%$ and relatively close. The deviation in the windward surfaces of the third group exceeds $4 \%$, which is a significant increase compared with that of the two previous groups. For the three other surfaces, the deviation in each face has the possibility of being the largest within the same group. The first group is the leeward surface (surface III) with a maximum of $5.32 \%$. The second group is the inner crosswind surface (surface II) with a maximum of $8.34 \%$. The outer crosswind surface (surface IV) is the largest in the third group at more than $12 \%$. Although the deviation values of surfaces II, III, and IV in the same group are non-identical, the difference is small. The influence of the overtaking behavior on the three surfaces is relatively similar. The overall deviation of all the 20 measurement points also increases with the relative velocity, such that $13 \mathrm{~km} / \mathrm{h}$ increases by $2.10 \%$ compared with $8 \mathrm{~km} / \mathrm{h}$. The overall deviation in $18 \mathrm{~km} / \mathrm{h}$ is $9.48 \%$, which increases by $3.35 \%$ over $13 \mathrm{~km} / \mathrm{h}$. The largest contribution to the overall deviation in all the 20 measurement points during overtaking is from surfaces II, III, and IV. Surface I is less influenced by the overtaking behavior. In general, the influence of overtaking behavior increases with the relative velocity under the constant velocity of the test vehicle.

At different relative velocities, the length of time during which the overtaking behavior influences the wind pressure coefficient and the relative displacement of the two vehicles corresponding to the length of time are shown in Figure 11. The large influence duration corresponds to the small relative displacement due to the difference in relative velocity. Hence, the change trend of relative displacement is opposite to that of the influence duration. The influence duration is the longest $(1.73 \mathrm{~s})$ when the relative velocity is $8 \mathrm{~km} / \mathrm{h}$, and the corresponding relative displacement of the two vehicles is $3.84 \mathrm{~m}$. The influence duration is the shortest (1.41 s) when the relative velocity is $18 \mathrm{~km} / \mathrm{h}$, and the corresponding relative displacement of the two vehicles is $7.05 \mathrm{~m}$. Therefore, the influence duration decreases with the increase in relative velocity, and the relative displacement of the two vehicles corresponding to the influence duration increases with the increase in relative velocity. 


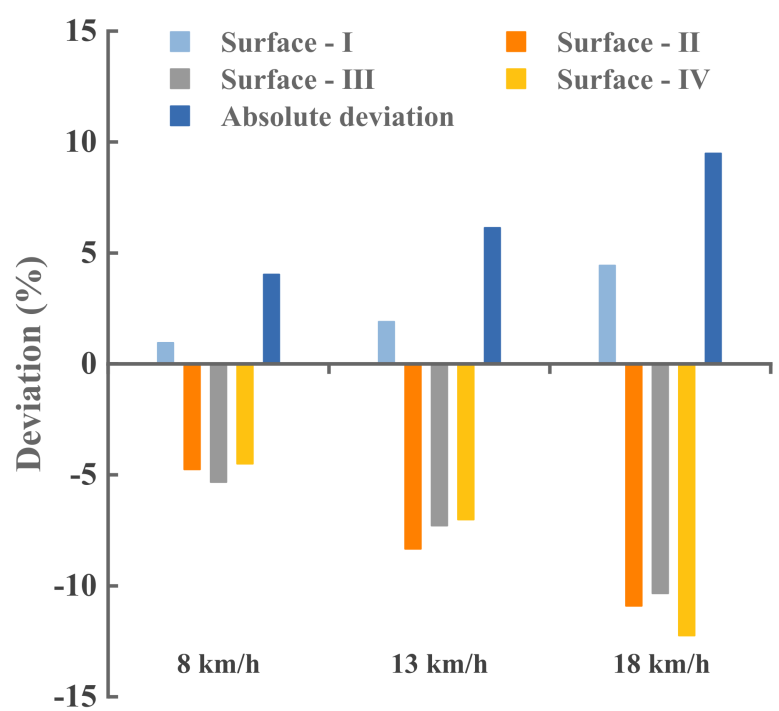

Figure 10. Deviation in the mean wind pressure coefficients at different relative velocities.

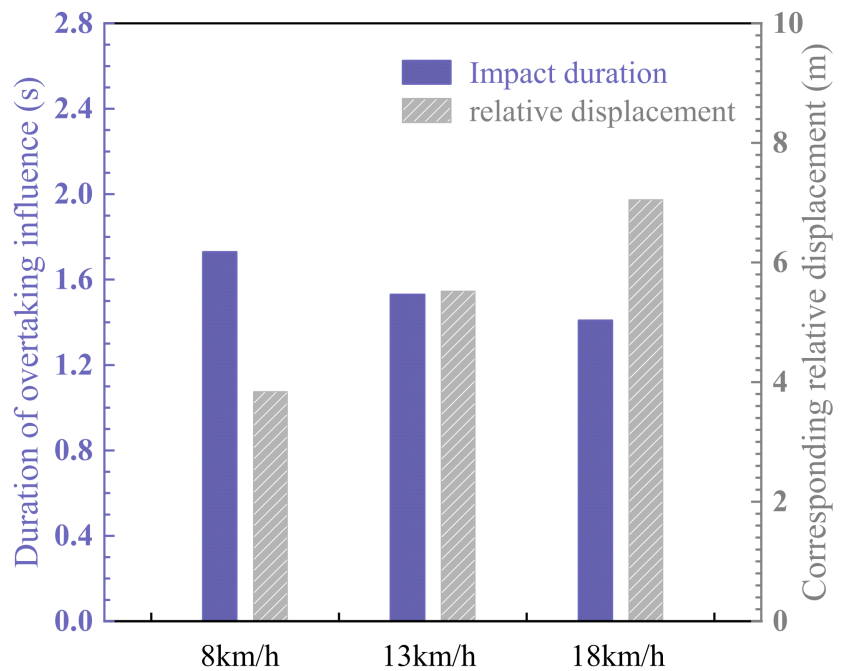

Figure 11. Duration of overtaking influence and the corresponding relative displacement at different relative velocities.

Given that the influence of overtaking behavior has a short duration and the degree of influence is minimal, the influence of overtaking behavior is analyzed from the perspective of the selection of data calculation time for calculating the mean wind pressure coefficient. At different relative velocities, the mean wind pressure coefficients calculated by selecting different data calculation times, including the overtaking period, are shown in Figure 12. The dotted line in the figure denotes the mean wind pressure coefficients calculated after excluding the overtaking period. By taking the three representative measurement points on surfaces II, III, and IV as an example, surface I is less influenced and excluded from the analysis. In the relative velocity of $8 \mathrm{~km} / \mathrm{h}$, the influence of overtaking behavior can be eliminated when the data calculation time takes more than $6 \mathrm{~s}$ (Figure 12a). In the relative velocity of $13 \mathrm{~km} / \mathrm{h}$, the consecutive calculation of duration is set to $10 \mathrm{~s}$ to ignore the influence of overtaking behavior (Figure 12b). However, in the relative velocity of $18 \mathrm{~km} / \mathrm{h}$, it takes more than $16 \mathrm{~s}$ to eliminate the overtaking influence (Figure 12c). Therefore, the data calculation time required to eliminate the overtaking influence increases with the relative velocity. 


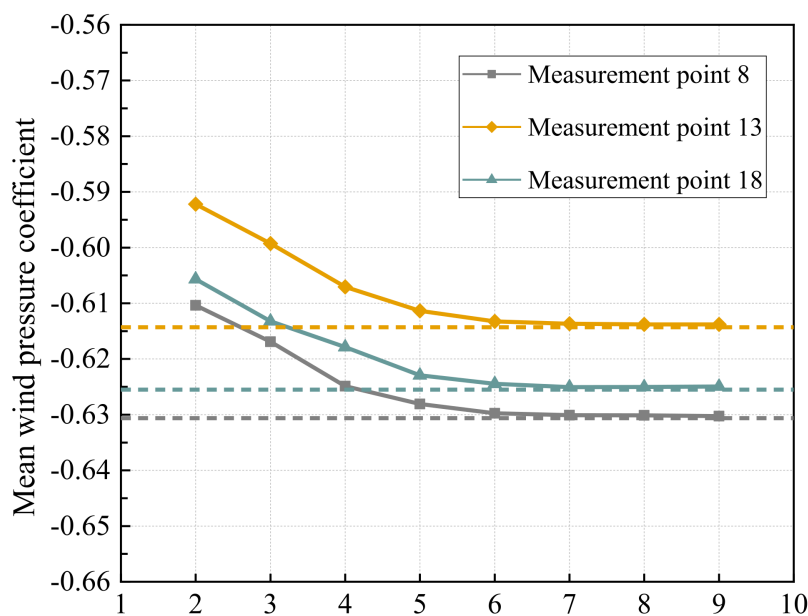

(a)

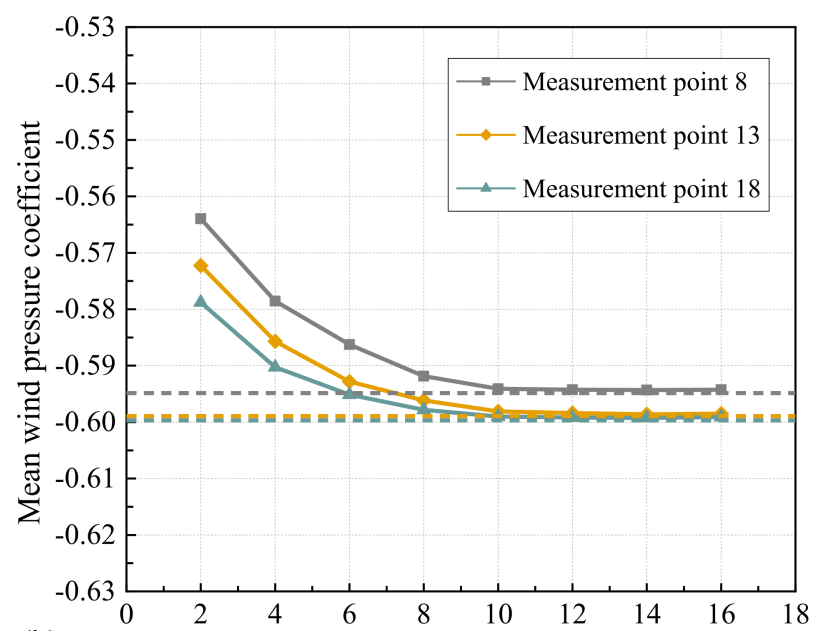

(b) Calculation time of mean wind pressure coefficient (s)

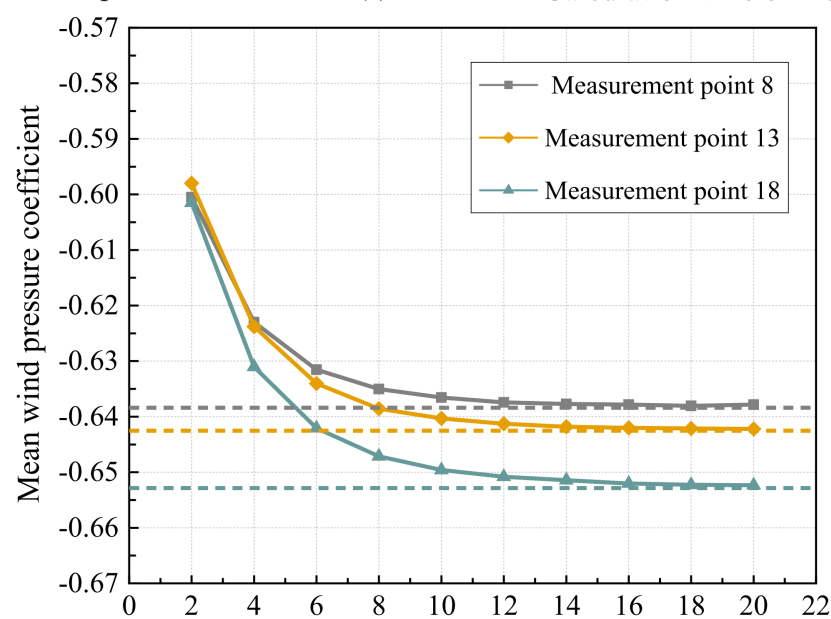

(c) Calculation time of mean wind pressure coefficient (s)

Figure 12. Mean wind pressure coefficients of representative measurement points with different data calculation times at a relative velocity of (a) 8 , (b) 13 , and (c) $18 \mathrm{~km} / \mathrm{h}$.

\subsection{Influence of Test Vehicle Velocity during Overtaking}

To investigate the influence of test vehicle velocity during overtaking, the relative velocity of $18 \mathrm{~km} / \mathrm{h}$ was kept constant in this section. The test vehicle velocities were set to 60,72 , and $90 \mathrm{~km} / \mathrm{h}$, and the overtaking behavior was still performed in the adjacent lanes. For test vehicle velocities of 60 and $90 \mathrm{~km} / \mathrm{h}$, the time history of the wind pressure coefficient of the representative measurement points is shown in Figures 13 and 14, respectively. The time history of the wind pressure coefficient at $72 \mathrm{~km} / \mathrm{h}$ is presented in Figure 8 . The result has the following law, which is the same as that in Section 3.1. The time history of wind pressure coefficient appears convex during the overtaking period, and the average value of the wind pressure coefficient during the overtaking period is higher than those before and after the overtaking period. Moreover, under the three test vehicle velocities, the fluctuation in the wind pressure coefficient of the windward surface during overtaking is significantly smaller than those of the three other surfaces. The fluctuations in surfaces II, III, and IV are very significant. 

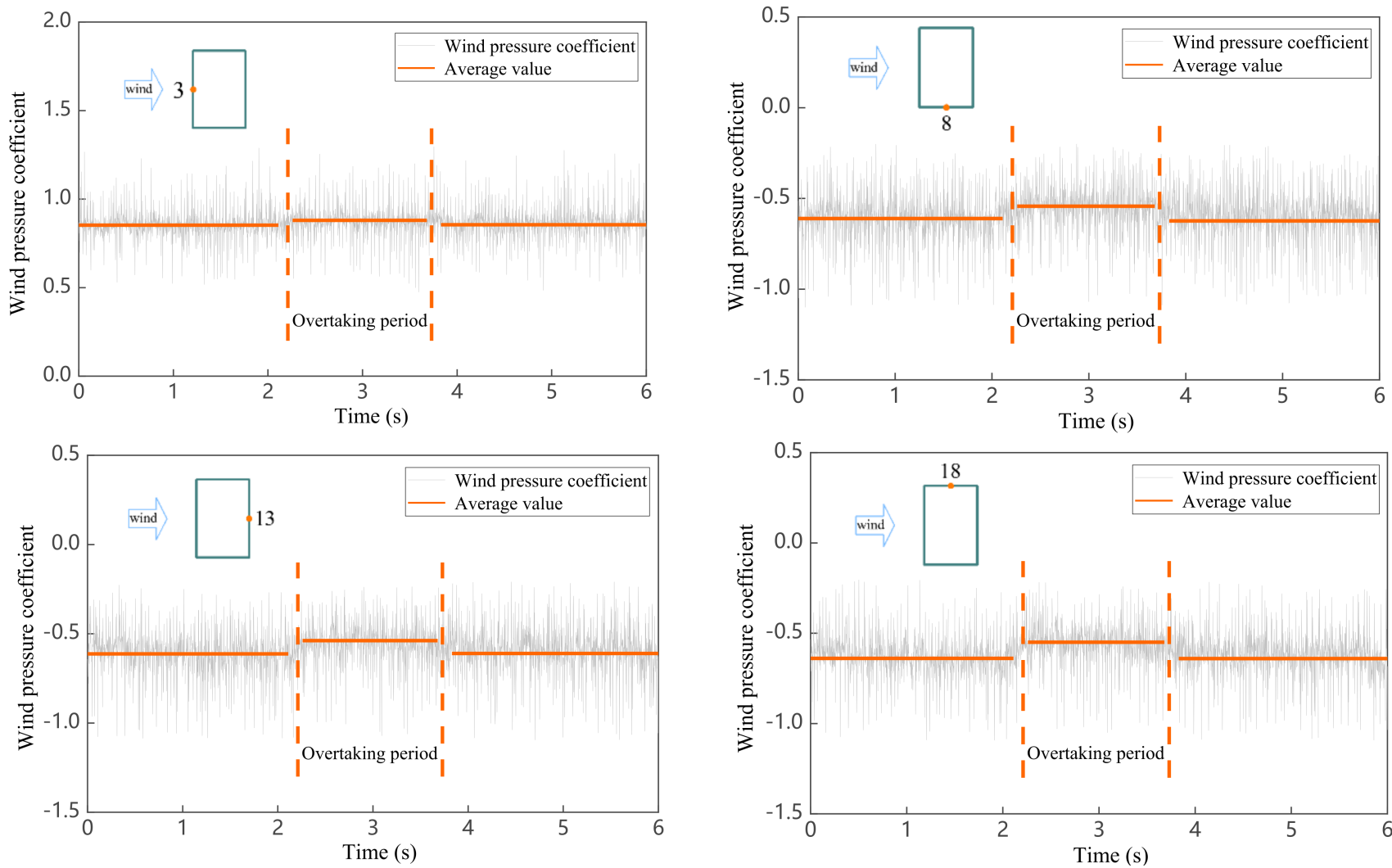

Figure 13. Time history of the wind pressure coefficient of measurement points $3,8,13$, and 18 when overtaking in the adjacent lane (test vehicle: $60 \mathrm{~km} / \mathrm{h}$, interference vehicle: $78 \mathrm{~km} / \mathrm{h}$ ).
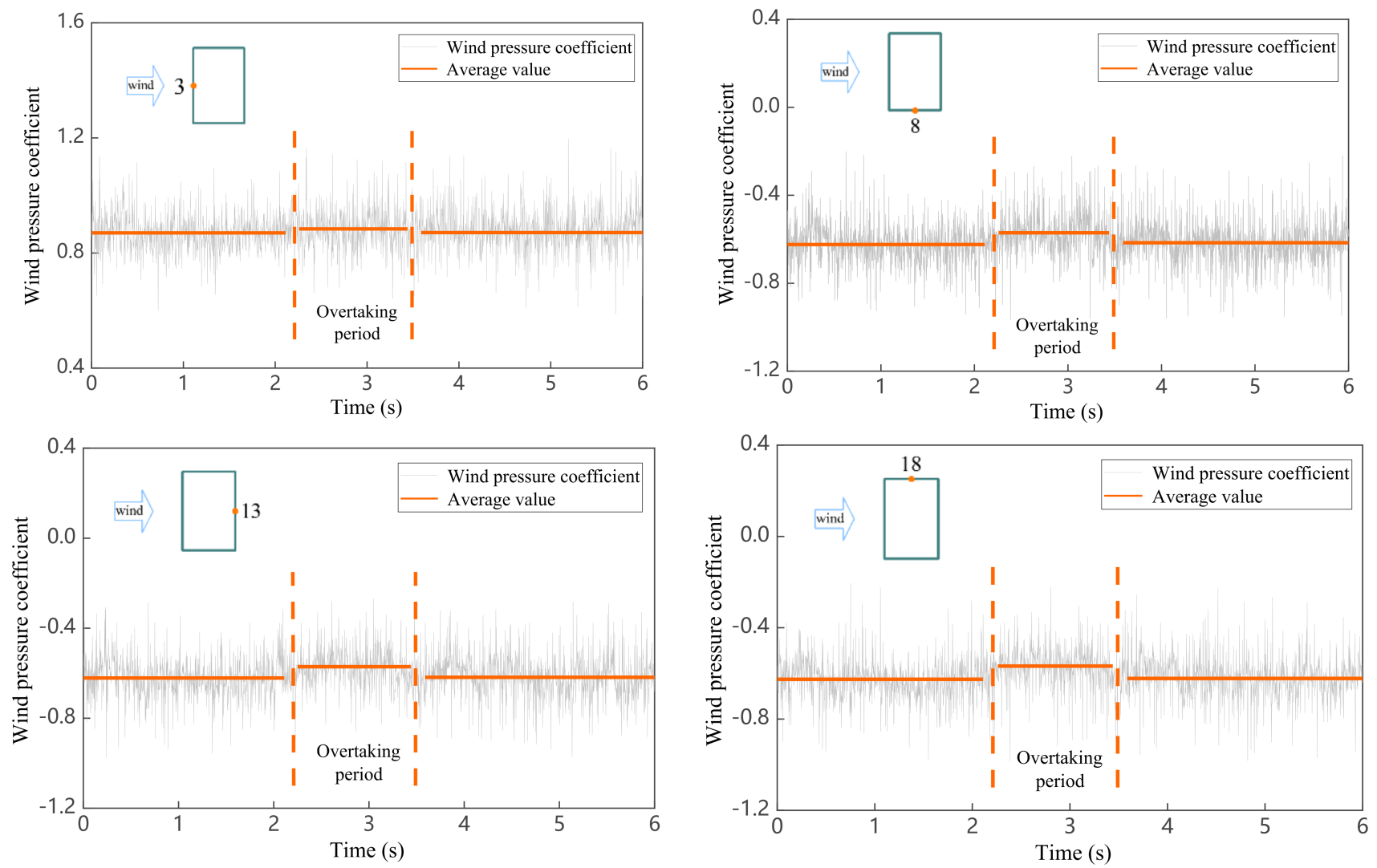

Figure 14. Time history of the wind pressure coefficient of measurement points $3,8,13$, and 18 when overtaking in the adjacent lane (test vehicle: $90 \mathrm{~km} / \mathrm{h}$, interference vehicle: $108 \mathrm{~km} / \mathrm{h}$ ). 
Figure 15 shows the mean wind pressure coefficients for each measurement point in the overtaking period and excluding the overtaking period at each test vehicle velocity. The results are also compared with those of the wind tunnel test $[34,35,47]$ and numerical simulation of smooth inflow [48]. The curves of the mean wind pressure coefficient in the overtaking period and excluding the overtaking period are consistent with that of the wind tunnel test results, and the overall trends are more consistent with the simulation result of smooth inflow. In general, the overtaking behavior only increases the value of the mean wind pressure coefficient at each measurement point and makes the curve deviate (especially reflected in the negative pressure area) but does not influence its overall trend.

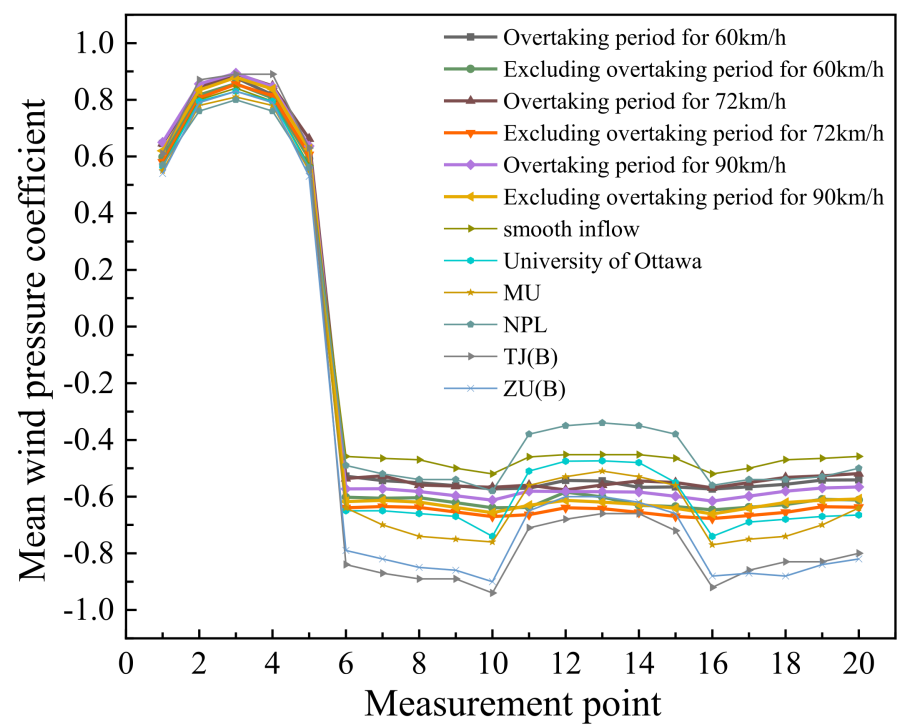

Figure 15. Mean wind pressure coefficients of each measurement point at different test vehicle velocities during the overtaking period and excluding the overtaking period.

The deviation in mean wind pressure coefficients due to the overtaking behavior at the three test vehicle velocities is shown in Figure 16. The deviation in windward surface is still the smallest among the four surfaces, and the deviation values at the three test vehicle velocities are similar at slightly higher than $4 \%$. Moreover, the proportion of the deviation, which is on the windward surface of the four faces in the same group, increases with the increase in test vehicle velocity and contributes more to the overall deviation. The three other surfaces have the same laws in which the high test vehicle velocity reduces the deviation. The same is true for the overall deviation in all measurement points, which decreases with the increase in test vehicle velocity. At the same relative velocity, the large test vehicle velocity reduces the influence caused by the overtaking behavior. This rule is consistent with that in Wu et al. [50].

Figure 17 shows the length of time with which the overtaking behavior influences the wind pressure coefficient and the relative displacements of the two vehicles corresponding to the length of time at different test vehicle velocities. Given that the relative velocities are the same, the overtaking influence duration is the same as the change trend in relative displacement within this time. When the test vehicle velocity is $60 \mathrm{~km} / \mathrm{h}$, the values of overtaking influence duration and relative displacement within this time are the largest at $1.52 \mathrm{~s}$ and $7.60 \mathrm{~m}$, respectively, and the vehicle velocity of $90 \mathrm{~km} / \mathrm{h}$ corresponds to the minimum of the two at $1.28 \mathrm{~s}$ and $6.40 \mathrm{~m}$, respectively. Hence, the overtaking influence duration and relative displacements of the two vehicles during this period decrease with the increase in test vehicle velocity. 


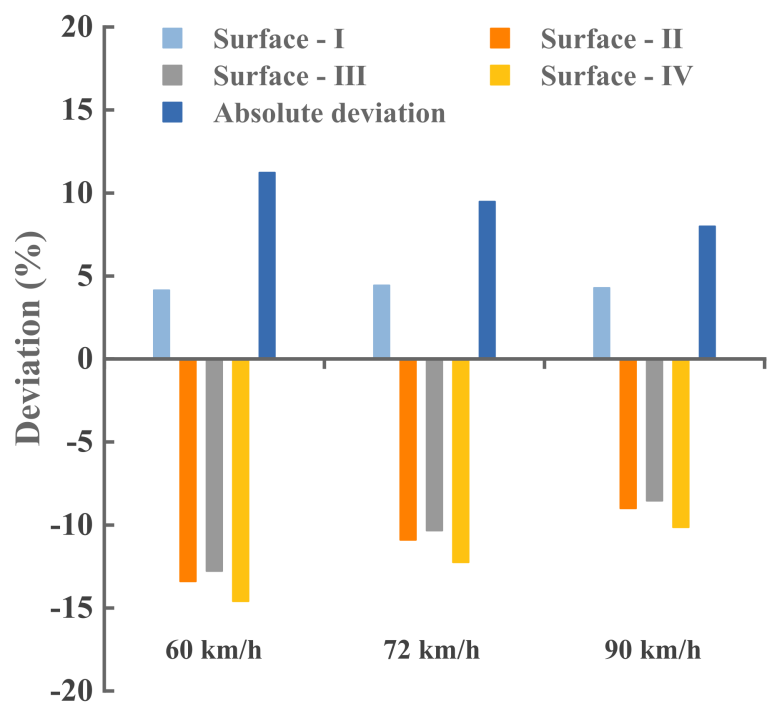

Figure 16. Deviation in the mean wind pressure coefficients at different test vehicle velocities.

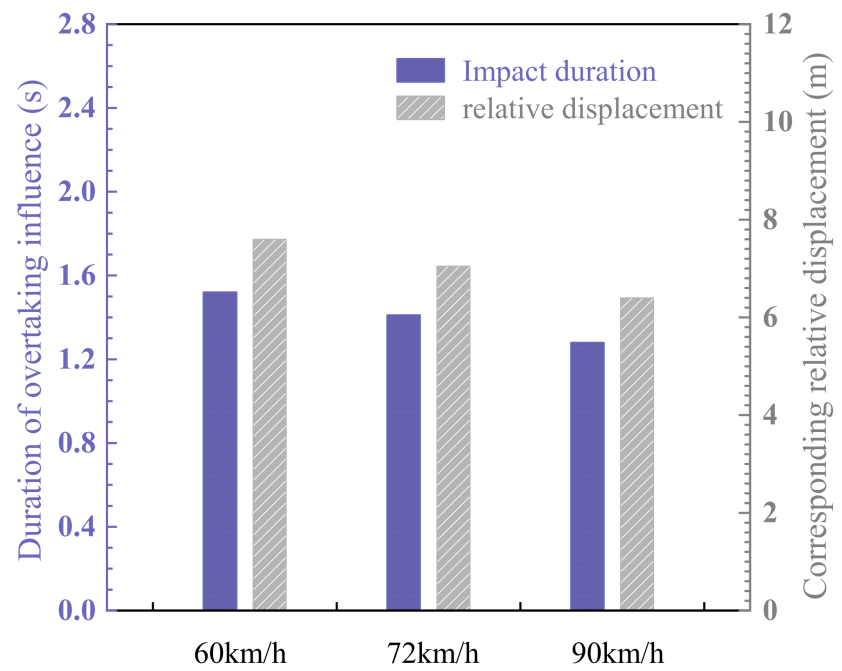

Figure 17. Duration of overtaking influence and the corresponding relative displacement at different test vehicle velocities.

For each test vehicle velocity, the mean wind pressure coefficients calculated from the different data calculation time (including the overtaking period) and the mean wind pressure coefficient calculated after excluding the overtaking period (dashed line) are shown in Figure 18. Similarly, the three representative measurement points on surfaces II, III, and IV are included in the analysis. At a test vehicle velocity of $90 \mathrm{~km} / \mathrm{h}$, the influence of overtaking behavior can be eliminated when the data calculation time is more than $12 \mathrm{~s}$ (Figure 18c). At a test vehicle velocity of $72 \mathrm{~km} / \mathrm{h}$, the consecutive calculation duration is set to $16 \mathrm{~s}$ to ignore the influence of overtaking behavior (Figure 18b). However, at a test vehicle velocity of $60 \mathrm{~km} / \mathrm{h}$, it takes more than $22 \mathrm{~s}$ to eliminate the overtaking influence (Figure 18a). Therefore, the data calculation time required to eliminate the overtaking influence decreases as the test vehicle velocity increases. 

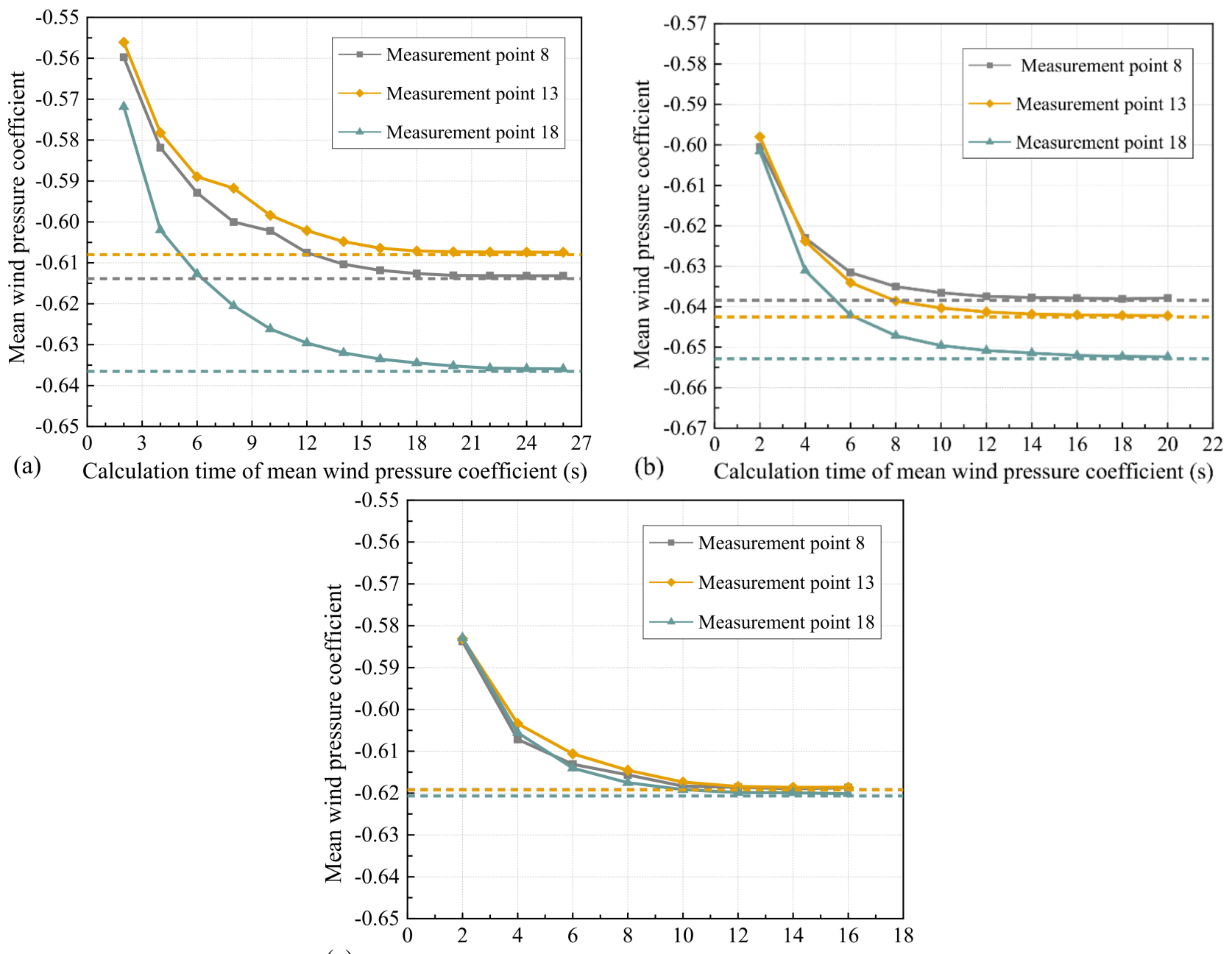

(c) Calculation time of mean wind pressure coefficient (s)

Figure 18. Mean wind pressure coefficients of representative measurement points with different data calculation times at a test vehicle velocity of (a) 60, (b) 72, and (c) $90 \mathrm{~km} / \mathrm{h}$.

\subsection{Influence of Overtaking Lanes}

As mentioned in Section 2.3, the two cases of overtaking are overtaking in the adjacent lanes and overtaking separated by one lane. The previous studies were all the case of overtaking in adjacent lanes. Then, it is concluded that overtaking behavior influences the wind pressure coefficients when the interference vehicle is separated by one lane beyond the test vehicle. In accordance with the results of the two previous sections, the test vehicle velocity was set as low, and the relative velocity was set as high to obtain the clear influence of overtaking behavior. Thus, in this section, the velocities of the test and interference vehicles are set to 60 and $90 \mathrm{~km} / \mathrm{h}$, respectively. The time history of the wind pressure coefficients of the four representative measurement points is shown in Figure 19. The time history of the wind pressure coefficient does not fluctuate significantly during the overtaking period, and the mean wind pressure coefficient during the overtaking period is similar to those before and after overtaking. The wind pressure coefficient of the model is unaffected by the overtaking behavior. By combining the pressure contour and the isosurface of velocity in Shao et al. [27], the two vehicles do not interfere with each other when their lateral distance is far enough. For the experiments in this section, the two vehicles are separated by one lane, and their lateral spacing is significantly large. To sum up, the overtaking behavior separated by one lane cannot constitute the influence on the wind pressure coefficient of the model, and the overtaking influence only originates from the overtaking situation in the adjacent lanes. 

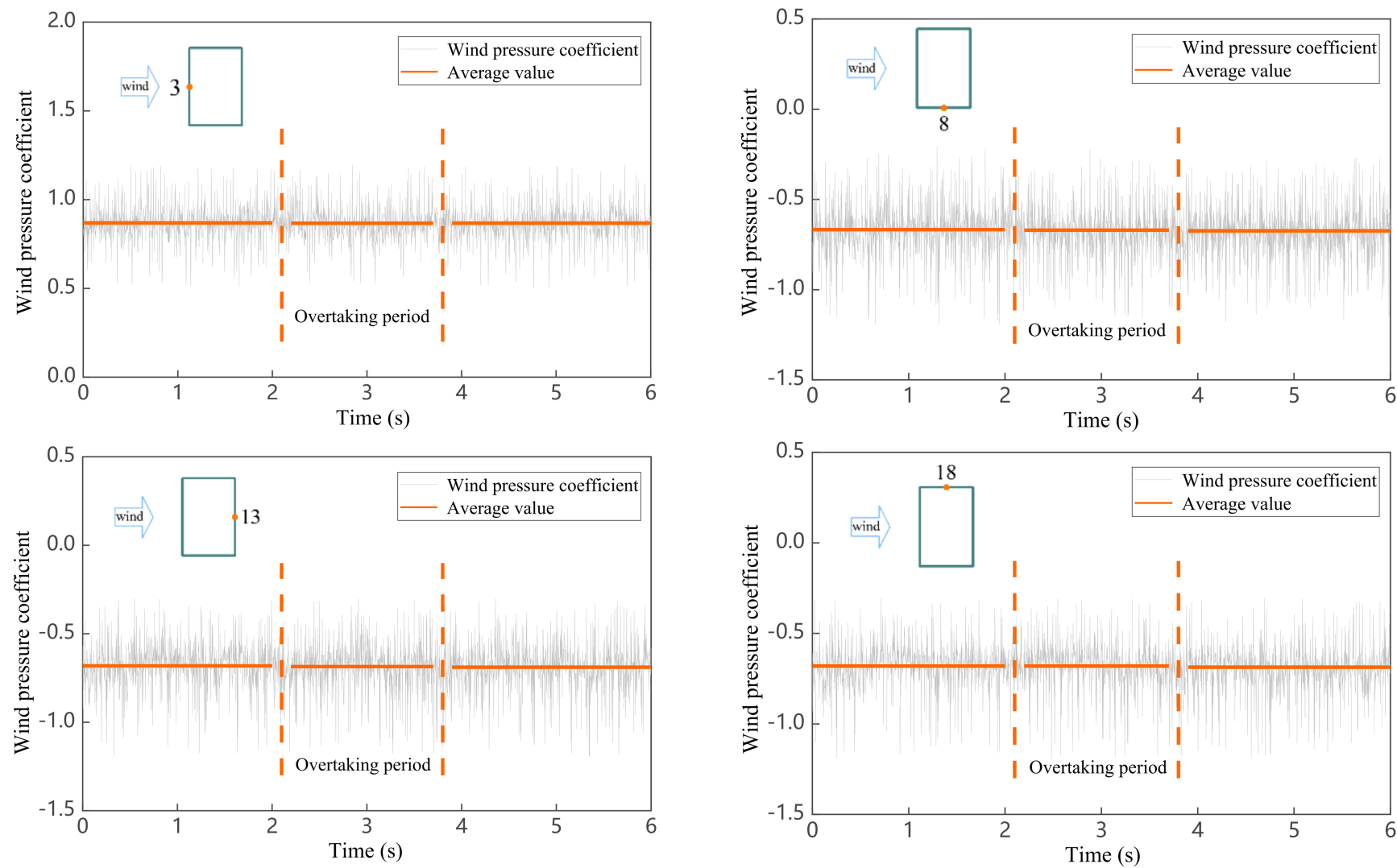

Figure 19. Time history of the wind pressure coefficient of measurement points $3,8,13$, and 18 when the overtaking behavior is separated by one lane (test vehicle: $60 \mathrm{~km} / \mathrm{h}$, interference vehicle: $90 \mathrm{~km} / \mathrm{h}$ ).

\subsection{Analysis of Test Vehicle Actively Overtaking}

The previous studies were all cases where the test vehicle was overtaken by small interference vehicle. Additionally, the situation of a test vehicle actively overtaking is investigated in this section. The velocities of the test vehicle and interference vehicle were set to $90 \mathrm{~km} / \mathrm{h}$ and $72 \mathrm{~km} / \mathrm{h}$, respectively. Figure 20 shows the results of the test vehicle actively overtaking the interference vehicle in the adjacent lane. It can be found that the wind pressure coefficient time histories of the four representative measurement points are stable throughout the whole process without significant fluctuations. In other words, the transiting test results are not affected. Combined with Section 3.3, the active overtaking behavior separated by one lane for the test vehicle will not affect the transiting test results.

In summary, the test results remain unaffected by the overtaking behavior when the test vehicle is the one actively overtaking, and the overtaking influence only occurs when the test vehicle is overtaken.

\subsection{Analysis of Wake Interference}

This section investigates the wake interference of the small interference vehicle on transiting test results, and aims to find a minimum vehicle spacing that is not disturbed by the wake of the small interference vehicle.

The two vehicles drove in the same lane, and the interference vehicle was in front of the test vehicle. According to previous research results, the test results are susceptible to interference at a small test vehicle velocity. Hence, the driving speed of the two vehicles was uniformly set to a minimum of $60 \mathrm{~km} / \mathrm{h}$, and following driving was maintained. The spacing, which is the distance between the tail of the interference vehicle and the head of the test vehicle, was measured by a laser rangefinder (TF03), and the data could be displayed and recorded in real time through supporting software. 

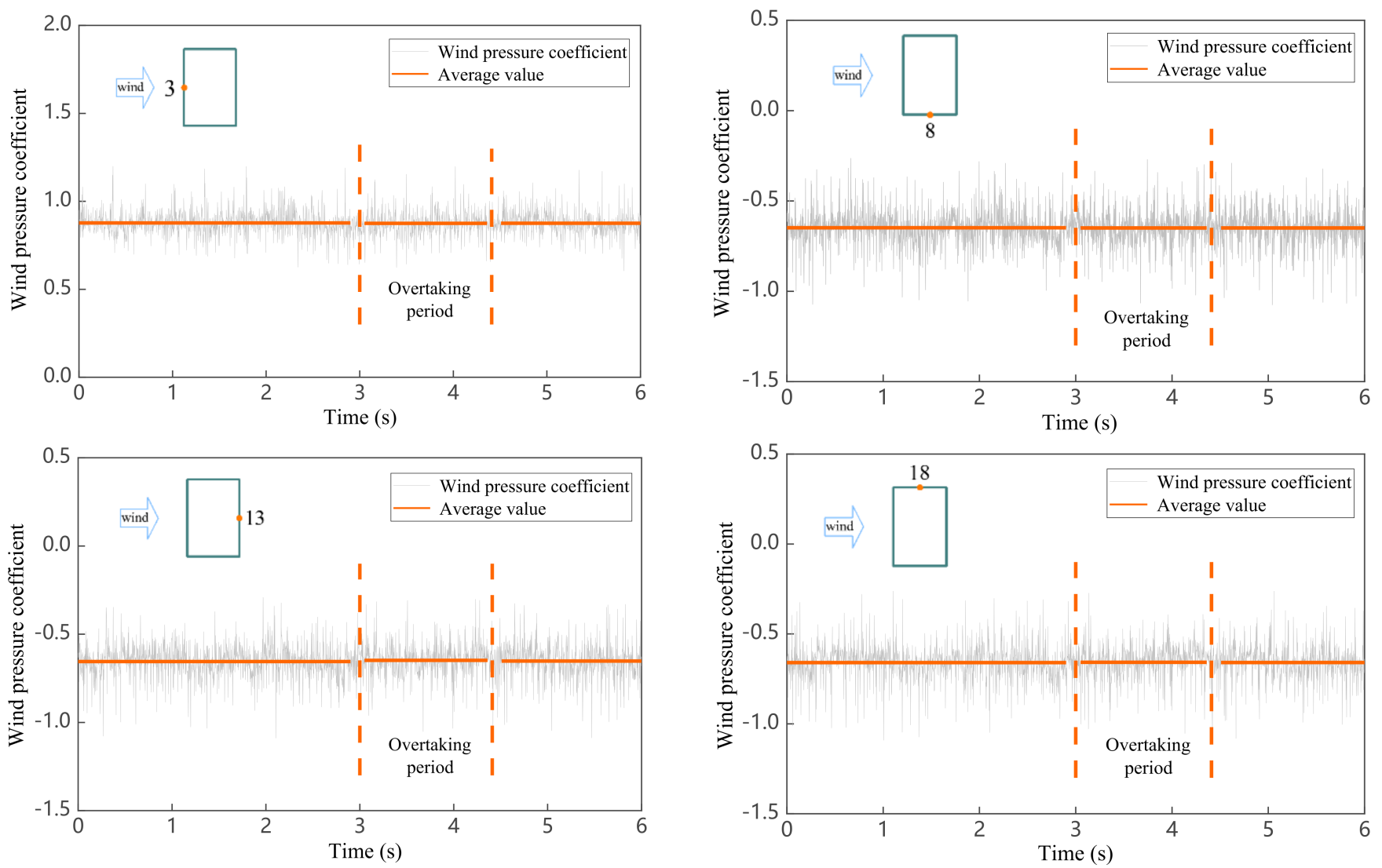

Figure 20. Time history of the wind pressure coefficient of measurement points $3,8,13$, and 18 when overtaking in the adjacent lane (test vehicle: $90 \mathrm{~km} / \mathrm{h}$, interference vehicle: $72 \mathrm{~km} / \mathrm{h}$ ).

Figure 21 shows the mean wind pressure coefficients of each measurement point at different spacings. The overall trends are consistent with that of the wind tunnel test results and similar to that of the simulation result of smooth inflow. Although the overall trends of mean wind pressure coefficient at different spacings are roughly the same, a relatively large difference exists in the value of the negative pressure area compared with that of the positive pressure area. The variation in the mean wind pressure coefficient at each measurement point with the spacing between the two vehicles is shown in Figure 22. The fluctuation in the windward surface is smaller than that of the three other surfaces. The mean wind pressure coefficient of each measurement point tends to stabilize after the spacing reaches $24 \mathrm{~m}$. In addition, the fluctuating wind pressure coefficient of each measurement point is also analyzed in Figure 23. When the spacing is small, the value of the fluctuating wind pressure coefficient at each measurement point and the fluctuation in the curve are large. After the spacing between the two vehicles reaches $24 \mathrm{~m}$, the fluctuating wind pressure coefficient curves begin to overlap and show a unified trend. The front vehicle in the same lane as the test vehicle no longer influences the test results after the spacing reaches $24 \mathrm{~m}$. 


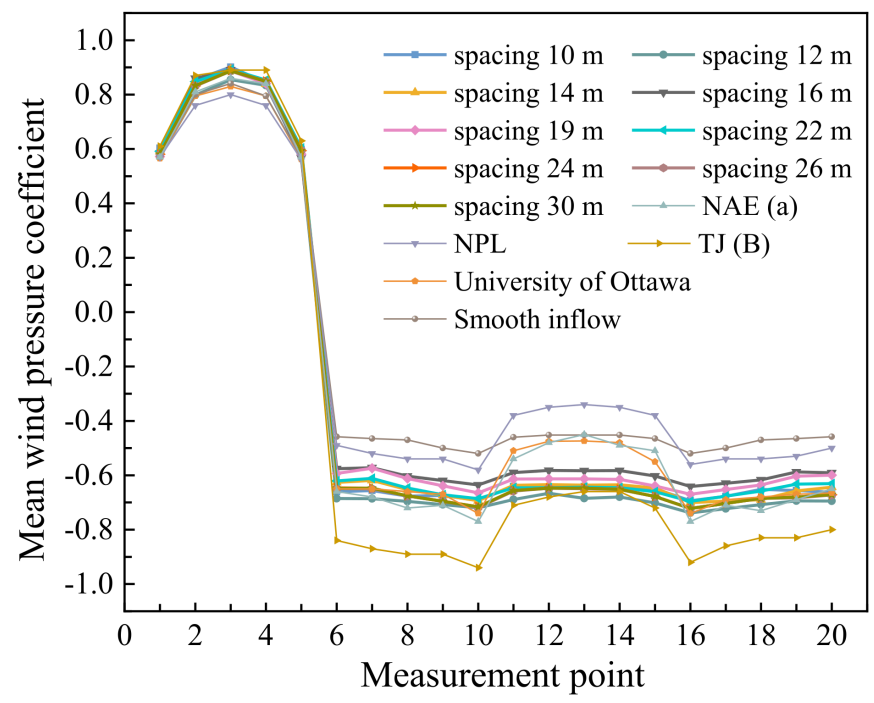

Figure 21. Mean wind pressure coefficients of each measurement point at different spacings.
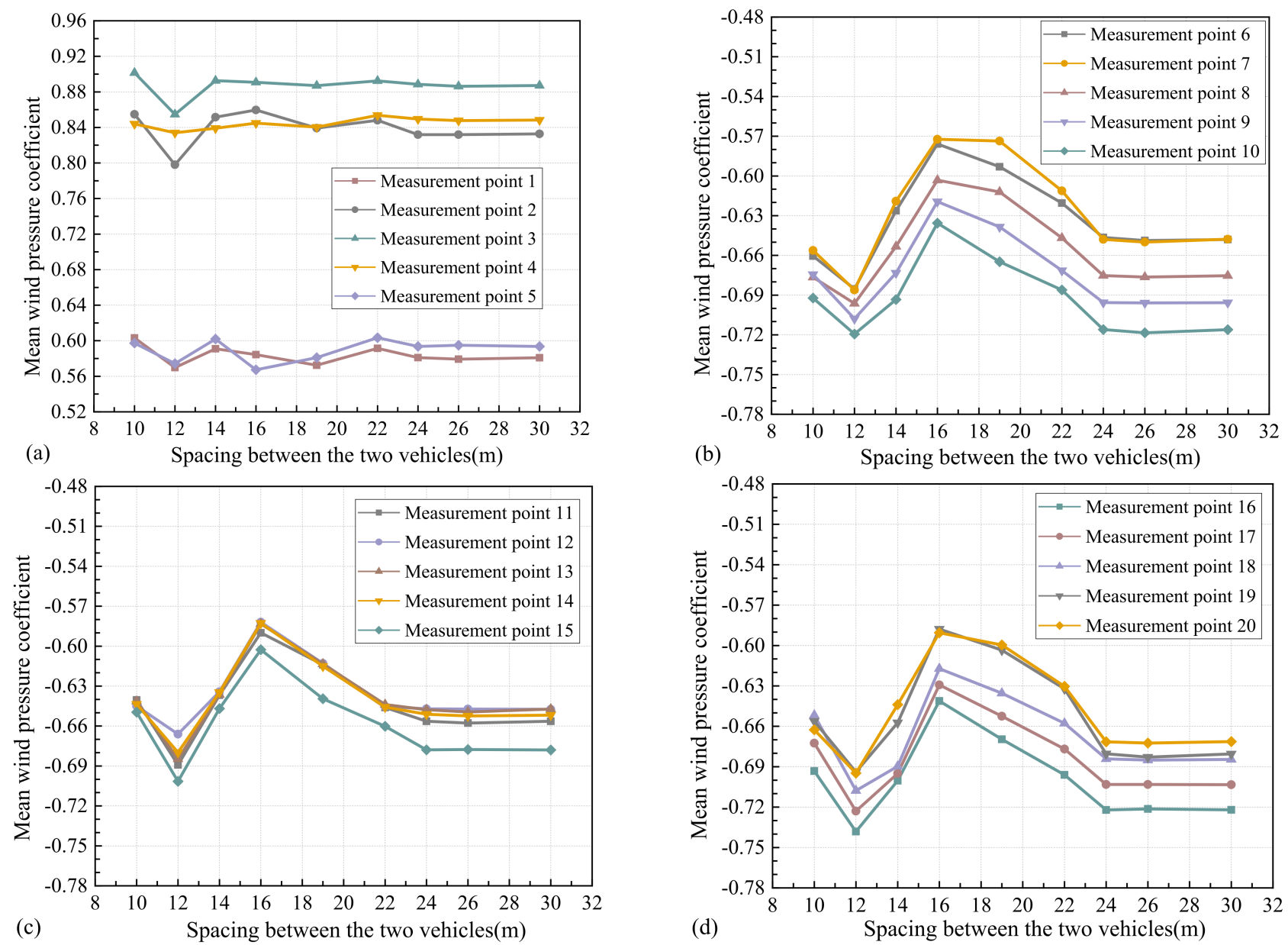

Figure 22. Variation in the mean wind pressure coefficient with different spacings. (a) Surface I; (b) surface II; (c) surface III; (d) surface IV. 


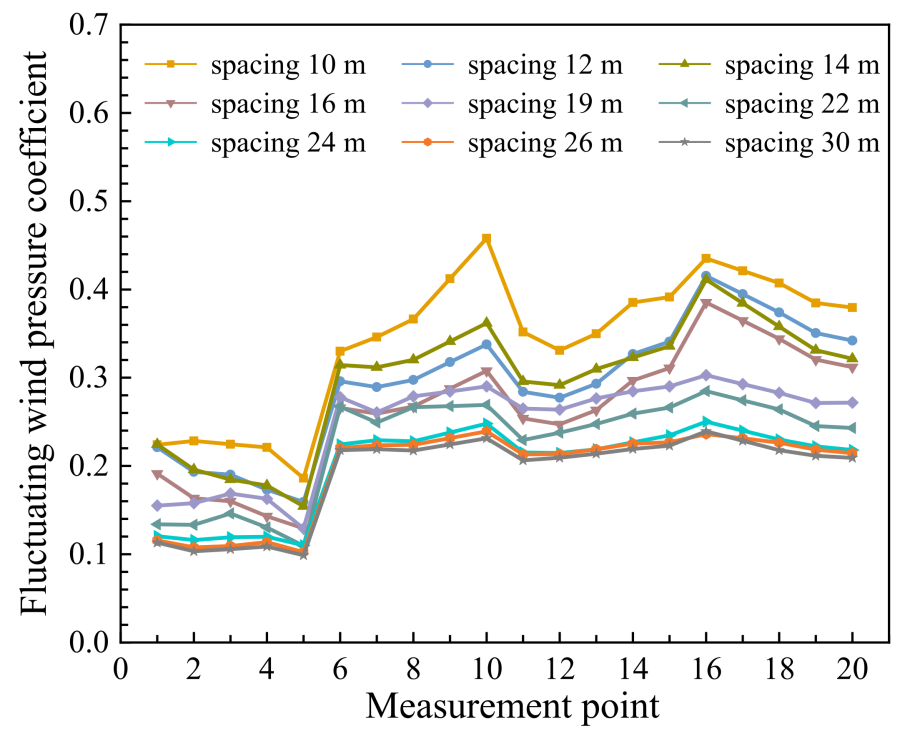

Figure 23. Fluctuating wind pressure coefficient of each measurement point at different spacings.

\section{Discussion}

Since the overtaking interference caused by the small interference vehicle is not too large, the method of extending the data calculation time is considered to eliminate the overtaking interference. According to the above experiment results, a minimum test vehicle velocity of $60 \mathrm{~km} / \mathrm{h}$ and a large relative velocity of $30 \mathrm{~km} / \mathrm{h}(90 \mathrm{~km} / \mathrm{h}$ for interference vehicle) were selected to obtain a larger overtaking interference. The overtaking process occurred in the adjacent lanes.

Figure 24 shows the mean wind pressure coefficients of the representative measurement points calculated by selecting the different data calculation times, including the overtaking period. The dotted line in the figure denotes the mean wind pressure coefficients calculated after the overtaking period is removed. As the calculation time increases, the three curves have a gradual downward trend, and the values gradually approach the mean wind pressure coefficient values under the condition of no interference, and reach stability after $26 \mathrm{~s}$. It can be seen that the calculation time of $26 \mathrm{~s}$ can eliminate the overtaking interference of a small vehicle on the mean wind pressure coefficients of the model. Figure 25 shows the fluctuating wind pressure coefficients at each measurement point during the overtaking interference period, the non-interference period, and the $26 \mathrm{~s}$ calculation time. It can be found that the fluctuating wind pressure coefficient curve under the $26 \mathrm{~s}$ calculation time almost coincides with the curve obtained during the non-interference period. Therefore, the calculation time of $26 \mathrm{~s}$ is feasible to eliminate the overtaking interference of a small vehicle on the fluctuating wind pressure coefficients. In summary, after the data calculation time exceeds $26 \mathrm{~s}$, the overtaking interference caused by the small vehicle can be eliminated.

Thus, in order to avoid the interference caused by a small vehicle, it is suggested for the experimental conditions of the transiting test method that the data calculation time needs to exceed $26 \mathrm{~s}$ and the vehicle spacing needs to exceed $24 \mathrm{~m}$. This paper is based on a large number of experiments and investigates the general situation of small vehicle interference during the transiting test. Therefore, the results are representative and can be directly used in transiting tests. The results of this paper provide specific guidance for transiting tests, and are of great significance to the development of the transiting test method. It is worth noting that the research in this paper is only aimed at a small interference vehicle, and the suggestions given are only used to avoid the interference caused by a small interference vehicle in transiting tests. The results in this paper can be used as a reference for the interference research of medium and large vehicles. 


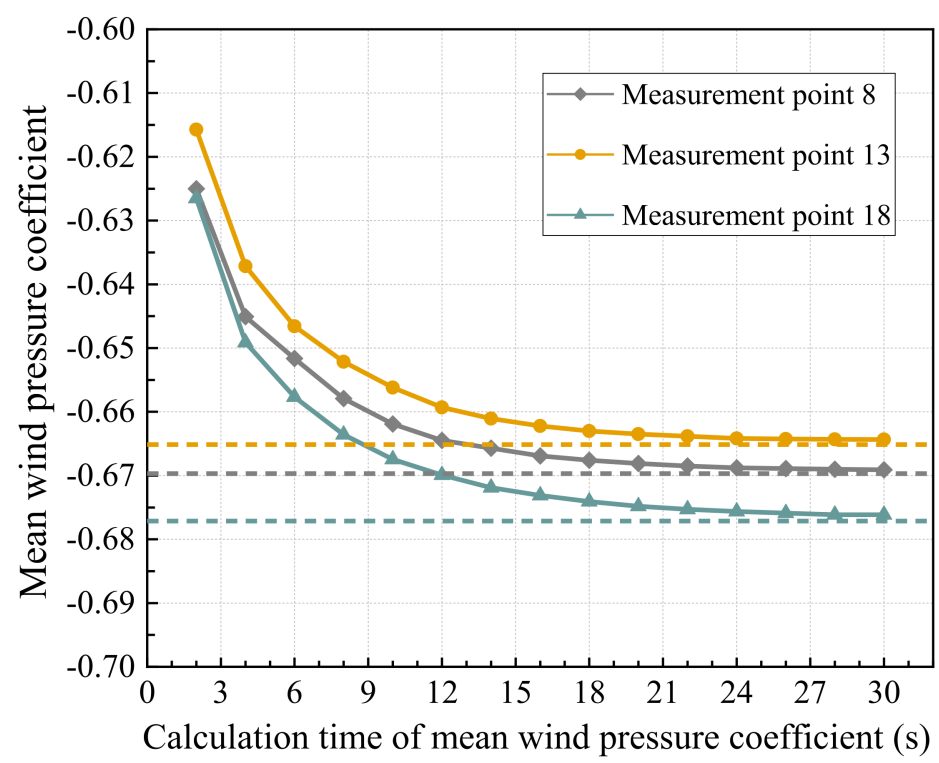

Figure 24. Mean wind pressure coefficients of the representative measurement points with different data calculation times $(60 \mathrm{~km} / \mathrm{h}$ test vehicle velocity and $30 \mathrm{~km} / \mathrm{h}$ relative velocity).

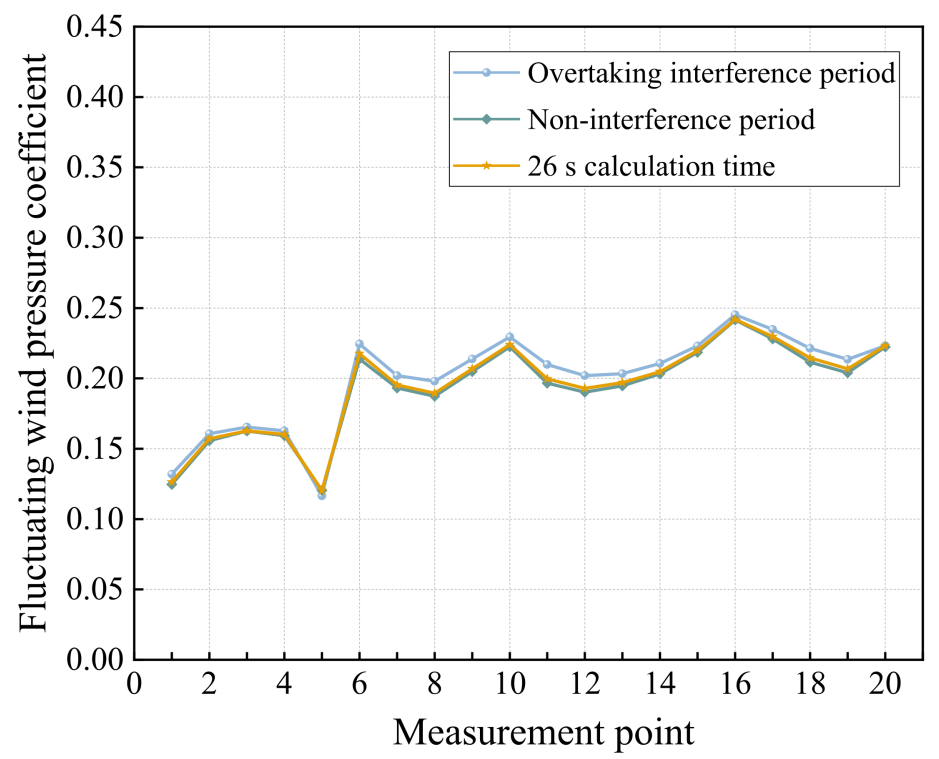

Figure 25. Comparison of fluctuating wind pressure coefficients under different calculation conditions.

\section{Conclusions}

The transiting test is a new experimental method for investigating structural wind resistance, which has the advantages of simplicity, low test cost, and no blocking effect compared with the wind tunnel test. However, the transiting test results can be influenced by some road environment factors. In this study, the influence of a small vehicle on the transiting test method for measuring building wind pressure coefficients was investigated from the perspective of overtaking and wake interference through experiments. The main conclusions of this study are presented as follows:

(1) The time history of the wind pressure coefficient of the model appears as a bulge during the overtaking period, especially in the negative pressure area. When the test vehicle velocity is constant, the overall trends of the mean wind pressure coefficient curves in the overtaking period and excluding the overtaking period are the same for each relative velocity. Comparatively, the negative pressure area has a larger value during the overtaking period. In addition, the influence of overtaking behavior 
increases with the relative velocity, and the duration of overtaking influence decreases with the increase in relative velocity. The relative displacement of the two vehicles during the overtaking period increases with the increase in relative velocity. The influence of overtaking behavior can be eliminated by extending the data calculation time, and the required data calculation time increases with the relative velocity.

(2) When the relative velocity is constant, the overall trends of the mean wind pressure coefficient curves in the overtaking period and excluding the overtaking period are basically the same under each test vehicle velocity. By contrast, the negative pressure area has a larger value during the overtaking period. The influence of overtaking behavior, the duration of overtaking influence, and the relative displacement of the two vehicles during the overtaking period decrease with the increase in test vehicle velocity. The data calculation time required to eliminate the overtaking influence decreases as the test vehicle velocity increases.

(3) The overtaking interference occurs only when the test vehicle is overtaken by the small interference vehicle in the adjacent lane.

(4) The wake of the small interference vehicle no longer influences the transiting test results after the spacing reaches $24 \mathrm{~m}$. The overtaking interference caused by the small vehicle can be eliminated after the data calculation time exceeds $26 \mathrm{~s}$.

(5) In order to avoid the interference caused by a small vehicle, combined with the actual conditions of the test road, it is suggested for the transiting test method that the data calculation time needs to exceed $26 \mathrm{~s}$ and the vehicle spacing needs to exceed $24 \mathrm{~m}$.

Author Contributions: Conceptualization, S.L.; Investigation, X.L., Q.L. and W.G.; Methodology, S.L. and P.G. All authors have read and agreed to the published version of the manuscript.

Funding: This research was funded by the National Natural Science Foundation of China (51778587, 51808510), Key Scientific and Technological Research Projects of Henan Province (212102310975, 192102310514), and Science and Technology Planning Project of Transportation in Henan Province (2018J3).

Institutional Review Board Statement: Not applicable.

Informed Consent Statement: Not applicable.

Data Availability Statement: Not applicable.

Conflicts of Interest: The authors declare no conflict of interest.

\section{References}

1. Yang, Q.; Gao, R.; Bai, F.; Li, T.; Tamura, Y. Damage to Buildings and Structures Due to Recent Devastating Wind Hazards in East Asia. Nat. Hazards 2018, 92, 1321-1353. [CrossRef]

2. Fang, Z.; Li, A.; Ding, Y.; Li, W. Wind-Induced Fatigue Assessment of Welded Connections in Steel Tall Buildings Using the Theory of Critical Distances. Eur. J. Environ. Civ. Eng. 2018, 24, 1-26. [CrossRef]

3. Fu, J.; Zheng, Q.; Huang, Y.; Wu, J.; Pi, Y.; Liu, Q. Design Optimization on High-Rise Buildings Considering Occupant Comfort Reliability and Joint Distribution of Wind Speed and Direction. Eng. Struct. 2018, 156, 460-471. [CrossRef]

4. Gu, M. Wind-Resistant Studies on Tall Buildings and Structures. Sci. China Technol. Sci. 2010, 53, 2630-2646. [CrossRef]

5. Elshaer, A.; Bitsuamlak, G.; El Damatty, A. Enhancing Wind Performance of Tall Buildings Using Corner Aerodynamic Optimization. Eng. Struct. 2017, 136, 133-148. [CrossRef]

6. Xu, A.; Sun, W.X.; Zhao, R.H.; Wu, J.R.; Ying, W.Q. Lateral Drift Constrained Structural Optimization of an Actual Supertall Building Acted by Wind Load. Struct. Des. Tall Spec. Build. 2017, 26, e1344. [CrossRef]

7. Guo, P.; Li, S.; Wang, D. Effects of Aerodynamic Interference on the Iced Straddling Hangers of Suspension Bridges by Wind Tunnel Tests. J. Wind Eng. Ind. Aerod. 2019, 184, 162-173. [CrossRef]

8. Li, S.; Guo, P.; Wang, C.; Hu, Y.; Wang, D. Influence of Catwalk Design Parameters on the Galloping of Constructing Main Cables in Long-Span Suspension Bridges. J. Vibroeng. 2017, 19, 4671-4684. [CrossRef]

9. Argentini, T.; Rocchi, D.; Somaschini, C. Effect of the Low-Frequency Turbulence on the Aeroelastic Response of a Long-Span Bridge in Wind Tunnel. J. Wind Eng. Ind. Aerod. 2020, 197, 104072. [CrossRef]

10. Guo, P.; Li, S.; Wang, D. Analysis of Wind Attack Angle Increments in Wind Tunnel Tests for the Aerodynamic Coefficients of Iced Hangers. Adv. Struct. Eng. 2019, 23, 603-613. [CrossRef]

11. Li, S.; An, Y.; Wang, C.; Wang, D. Experimental and Numerical Studies on Galloping of the Flat-Topped Main Cables for the Long Span Suspension Bridge During Construction. J. Wind Eng. Ind. Aerod. 2017, 163, 24-32. [CrossRef] 
12. Li, S.; Zheng, S. Aerodynamic Performance Analysis of Wind-Sand Flow on Riding-Type Hangers of Suspension Bridges. J. Vibroeng. 2017, 19, 1301-1313. [CrossRef]

13. An, Y.; Wang, C.; Li, S.; Wang, D. Galloping of Steepled Main Cables in Long-Span Suspension Bridges During Construction. Wind Struct. 2016, 23, 595-613. [CrossRef]

14. Zhang, J.W.; Li, Q.S. Field Measurements of Wind Pressures on a $600 \mathrm{~m}$ High Skyscraper during a Landfall Typhoon and Comparison with Wind Tunnel Test. J. Wind Eng. Ind. Aerod. 2018, 175, 391-407. [CrossRef]

15. Yu, C.; Li, Y.; Zhang, M.; Zhang, Y.; Zhai, G. Wind Characteristics along a Bridge Catwalk in a Deep-Cutting Gorge from Field Measurements. J. Wind Eng. Ind. Aerod. 2019, 186, 94-104. [CrossRef]

16. Li, S.L.; Liu, L.L.; Wu, H.; Jiang, N.; Zheng, S.Y.; Guo, P. New Test Method of Wind Pressure Coefficient Based on CAARC Standard Model Determined Using Vehicle Driving Wind. Exp. Tech. 2019, 43, 707-717. [CrossRef]

17. Li, S.; Liang, J.; Zheng, S.; Jiang, N.; Liu, L.; Guo, P. A Novel Test Method for Aerodynamic Coefficient Measurements of Structures Using Wind Generated by a Moving Vehicle. Exp. Tech. 2019, 43, 677-693. [CrossRef]

18. Li, S.; Wan, R.; Wang, D.; Guo, P. Effect of End Plates on Transiting Test for Measuring the Aerodynamic Coefficient of Structures Using Wind Generated by a Moving Vehicle. J. Wind Eng. Ind. Aerod. 2019, 190, 273-286. [CrossRef]

19. Guo, P.; Wang, D.; Li, S.; Liu, L.; Wang, X. Transiting Test Method for Galloping of Iced Conductor Using Wind Generated by a Moving Vehicle. Wind Struct. 2019, 28, 155-170.

20. Duncan, B.; D’Alessio, L.; Gargoloff, J.; Alajbegovic, A. Vehicle Aerodynamics Impact of On-Road Turbulence. Proc. Inst. Mech. Eng. Part D: J. Automob. Eng. 2017, 231, 1148-1159. [CrossRef]

21. Liu, L.; Sun, Y.; Chi, X.; Du, G.; Wang, M. Transient Aerodynamic Characteristics of Vans Overtaking in Crosswinds. J. Wind Eng. Ind. Aerod. 2017, 170, 46-55. [CrossRef]

22. Liu, L.; Wang, X.; Du, G.; Liu, Z.; Lei, L. Transient Aerodynamic Characteristics of Vans during the Accelerated Overtaking Process. J. Hydrodyn. 2018, 30, 357-364. [CrossRef]

23. Kremheller, A. Aerodynamic Interaction Effects and Surface Pressure Distribution during On-Road Driving Events. SAE Int. J. Passeng. Cars-Mech. Syst. 2015, 8, 165-176. [CrossRef]

24. Noger, C.; Van Grevenynghe, E. On the Transient Aerodynamic Forces Induced on Heavy and Light Vehicles in Overtaking Processes. Int. J. Aerod. 2011, 1, 373-383. [CrossRef]

25. Sun, H.; Karadimitriou, E.; Li, X.M.; Mathioulakis, D. Aerodynamic Interference between Two Road Vehicle Models during Overtaking. J. Energ. Eng. 2019, 145, 04019002. [CrossRef]

26. Howell, J.; Garry, K.; Holt, J. The Aerodynamics of a Small Car Overtaking a Truck. SAE Int. J. Passeng. Cars-Mech. Syst. 2014, 7, 626-638. [CrossRef]

27. Shao, N.; Yao, G.; Zhang, C.; Wang, M. A Research into the Flow and Vortex Structures Around Vehicles during Overtaking Maneuver with Lift Force Included. Adv. Mech. Eng. 2017, 9, 1687814017732892. [CrossRef]

28. Corin, R.J.; He, L.; Dominy, R.G. A CFD Investigation into the Transient Aerodynamic Forces on Overtaking Road Vehicle Models. J. Wind Eng. Ind. Aerod. 2008, 96, 1390-1411. [CrossRef]

29. Uystepruyst, D.; Krajnović, S. Numerical Simulation of the Transient Aerodynamic Phenomena Induced by Passing Manoeuvres. J. Wind Eng. Ind. Aerod. 2013, 114, 62-71. [CrossRef]

30. Watkins, S.; Vino, G. The Effect of Vehicle Spacing on the Aerodynamics of a Representative Car Shape. J. Wind Eng. Ind. Aerod. 2008, 96, 1232-1239. [CrossRef]

31. Noger, C.; Regardin, C.; Széchényi, E. Investigation of the Transient Aerodynamic Phenomena Associated with Passing Manoeuvres. J. Fluids Struct. 2005, 21, 231-241. [CrossRef]

32. Kui, H.; Xu, X.; Li, M.; Tian, C. Effect of Lateral Wind and Longitudinal Spacing on the Two Trucks in Tandem. J. Jilin Univ. 2016, $46,1426-1431$.

33. Robertson, F.H.; Bourriez, F.; He, M.; Soper, D.; Baker, C.; Hemida, H.; Sterling, M. An Experimental Investigation of the Aerodynamic Flows Created by Lorries Travelling in a Long Platoon. J. Wind Eng. Ind. Aerod. 2019, 193, 103966. [CrossRef]

34. Melbourne, W.H. Comparison of Measurements on the CAARC Standard Tall Building Model in Simulated Model Wind Flows. J. Wind Eng. Ind. Aerod. 1980, 6, 73-88. [CrossRef]

35. Tanaka, H.; Lawen, N. Test on the CAARC Standard Tall Building Model with a Length Scale of 1:1000. J. Wind Eng. Ind. Aerod. 1986, 25, 15-29. [CrossRef]

36. Braun, A.L.; Awruch, A.M. Aerodynamic and Aeroelastic Analyses on the CAARC Standard Tall Building Model Using Numerical Simulation. Comput. Struct. 2009, 87, 564-581. [CrossRef]

37. Daniels, S.J.; Castro, I.P.; Xie, Z.T. Peak Loading and Surface Pressure Fluctuations of a Tall Model Building. J. Wind Eng. Ind. Aerod. 2013, 120, 19-28. [CrossRef]

38. Sheng, R.; Perret, L.; Calmet, I.; Demouge, F.; Guilhot, J. Wind Tunnel Study of Wind Effects on a High-Rise Building at a Scale of 1:300. J. Wind Eng. Ind. Aerod. 2018, 174, 391-403. [CrossRef]

39. Huang, M.F.; Lau, I.W.H.; Chan, C.M.; Kwok, K.C.S.; Li, G. A Hybrid RANS and Kinematic Simulation of Wind Load Effects on Full-Scale Tall Buildings. J. Wind Eng. Ind. Aerod. 2011, 99, 1126-1138. [CrossRef]

40. Elshaer, A.; Aboshosha, H.; Bitsuamlak, G.; El Damatty, A.; Dagnew, A. LES Evaluation of Wind-Induced Responses for an Isolated and a Surrounded Tall Building. Eng. Struct. 2016, 115, 179-195. [CrossRef] 
41. Liu, Z.; Zheng, C.; Wu, Y.; Flay, R.G.J.; Zhang, K. Investigation on the effects of twisted wind flow on the wind loads on a square section megatall building. J. Wind Eng. Ind. Aerod. 2019, 191, 127-142. [CrossRef]

42. Chevula, S.; Sanz-Andres, Á.; Franchini, S. Estimation of the Correction Term of Pitot Tube Measurements in Unsteady (Gusty) Flows. Flow Meas. Instrum. 2015, 46, 179-188. [CrossRef]

43. Bhautmage, U.; Gokhale, S. Effects of Moving-Vehicle Wakes on Pollutant Dispersion Inside a Highway Road Tunnel. Environ. Pollut. 2016, 218, 783-793. [CrossRef]

44. Gao, Z.; Zhai, R.; Wang, P.; Yan, X.; Qin, H.; Tang, Y.; Ramesh, B. Synergizing Appearance and Motion with Low Rank Representation for Vehicle Counting and Traffic Flow Analysis. IEEE Trans. Intell. Transp. Syst. 2018, 19, 2675-2685. [CrossRef]

45. Lichtneger, P.; Ruck, B. Full Scale Experiments on Vehicle Induced Transient Pressure Loads on Roadside Walls. J. Wind Eng. Ind. Aerod. 2018, 174, 451-457. [CrossRef]

46. Lichtneger, P.; Ruck, B. Full Scale Experiments on Vehicle Induced Transient Loads on Roadside Plates. J. Wind Eng. Ind. Aerod. 2015, 136, 73-81. [CrossRef]

47. Meng, F.Q.; He, B.J.; Zhu, J.; Zhao, D.X.; Darko, A.; Zhao, Z.Q. Sensitivity Analysis of Wind Pressure Coefficients on CAARC Standard Tall Buildings in CFD Simulations. J. Build. Eng. 2018, 16, 146-158. [CrossRef]

48. Zhang, Y.; Habashi, W.G.; Khurram, R.A. Predicting Wind-Induced Vibrations of High-Rise Buildings Using Unsteady CFD and Modal Analysis. J. Wind Eng. Ind. Aerod. 2015, 136, 165-179. [CrossRef]

49. Lee, B.E. The Effect of Turbulence on the Surface Pressure Field of a Square Prism. J. Fluid Mech. 1975, 69, 263-282. [CrossRef]

50. Wu, Y.; He, B.; Fu, L. Influence of Velocity on Transient Aerodynamic Characteristics of Overtaking and Overtaken Vehicles. J. Jilin Univ. 2007, 37, 1009-1013. 